\title{
22. CORRELATION BETWEEN DIVERSE SEISMIC AND PHYSICAL PROPERTIES DATA SETS: SITE 763, SOUTHERN EXMOUTH PLATEAU 1
}

\author{
J. M. Lorenzo ${ }^{2,3}$ and E. E. Vera ${ }^{2}$
}

\begin{abstract}
Five major reflectors in multichannel seismic common-depth-point line 667 (acquired with an airgun source), single-channel seismic ODP line 5 (acquired with a high-resolution watergun), and expanded spread profile C2 can be dated and tied to lithologic units with results obtained during drilling of Site 763 . Through an initial $\tau$-sum construction, followed by traveltime and full waveform forward modeling, ESP-derived compressional wave velocities can more accurately match traveltimes of these reflectors than full-reflectivity synthetic seismograms produced from shipboard-derived properties. Instrument calibration, drilling disturbance, and rebound effects suffered by the laboratory samples are sources of error. We speculate, based on the physical properties of the units that reflector " $b$ " $(\sim 2 \mathrm{~s}$ TWT $)$ marks a decrease in the degree of induration of upper Oligocene chalk. Reflector " $c$ " marks the Cretaceous/Tertiary unconformity; " $\mathrm{e} "(\sim 2.25 \mathrm{~s})$ marks the abrupt disappearance of the terrigenous component of the sediments at the Cenomanian/Turonian boundary in response to the disappearance of the clastic supply; " $\mathrm{f}$ " $(\sim 2.4 \mathrm{~s})$ is found above a breakup unconformity; and " $\mathrm{g}$ " $(\sim 3.15 \mathrm{~s})$ arises near the top of the Triassic pre-rift basement in a thin $(50 \mathrm{~m})$ high-velocity $(4 \mathrm{~km} / \mathrm{s})$ region of shallow-water reefal limestones.
\end{abstract}

\section{INTRODUCTION}

The Exmouth Plateau (Fig. 1) is an unusually broad region of continental crust, deformed during Jurassic rifting that preceded Early Cretaceous seafloor spreading in the adjacent Indian Ocean (Powell, 1976; Veevers and Cotterill, 1978; Larson et al., 1979; Falvey and Mutter, 1981). Extensive commercial and some Australian government-sponsored reflection seismic coverage, dredging, and exploration drilling have allowed a detailed structural stratigraphic history to be drawn for most of the plateau (Exon and Willcox, 1978, 1980; Barber, 1982; von Stackelberg et al., 1980). The southern Exmouth Plateau which is the focus of this study, forms part of a starved passive continental margin (von Rad and Exon, 1983).

Recently, Ocean Drilling Program (ODP) drilling at Sites 762 and 763 verified the general stratigraphic and structural description for the central and southern Exmouth Plateau (Haq et al., 1988; Haq, von Rad, O'Connell, et al., 1990). Prior to drilling, the major seismic horizons on the southern Exmouth Plateau and their proposed ages had been based largely on the continuity and similarity of their characteristics in seismic profiles extrapolated over large distances from tie points at commercial wells (Exon and Willcox, 1976). What remains is to improve this correlation by tying the local reflection seismic horizons to the physical properties changes, and lithostratigraphic and biostratigraphic units, seen in the wells.

The physical properties data cannot be directly compared with the recorded seismic data. Instead, reflection coefficient series and synthetic seismograms (normal incidence case) calculated from the physical properties are used. At normal incidence, synthetic seismogram calculations require values for compressional wave velocity $\left(V_{p}\right)$ and bulk density $(\rho)$ as a

\footnotetext{
1 von Rad, U., Haq, B. U., et al., 1992. Proc. ODP, Sci. Results, 122: College Station, TX (Ocean Drilling Program).

2 Lamont-Doherty Geological Observatory of Columbia University, Palisades, NY 10964, U.S.A.

${ }^{3}$ Current address: School of Earth Sciences, Flinders University of South Australia, G.P.O. Box 2100, Adelaide 5001, Australia.
}

function of depth. An accurate match between the physical properties and recorded seismic data can be used to examine which changes in the lithology create the seismic impedance $\left(V_{p} \times\right.$ in-situ $\left.\rho\right)$ contrasts that produce the observed reflection horizons.

Because of a high core recovery (greater than $81 \%$ ) at Site 763 , shipboard values for $V_{p}$ and wet-bulk density were determined every $3 \mathrm{~m}$ on average to $1032.79 \mathrm{~m}$ below seafloor (mbsf), near the bottom of the well. Grain density, porosity, and water content (see "Explanatory Notes" chapter, Haq, von Rad, O'Connell, et al., 1990) were also measured to fully characterize the physical properties of the sediments. Additional in-situ $V_{p}$ measurements were obtained for approximately the middle third of the drilled interval of Site 763 and for most of a nearby industry well, Vinck-1. Site 763 was chosen to double nearby Vinck-1 and prevent any unexpected encounter with hazardous formation fluids because the drilling vessel JOIDES Resolution is not equipped to contain highly overpressured hydrocarbon fluids.

Figure 2 displays the projected locations of three different, contiguous seismic data sets that can be tied to geological units at Site 763. Single-channel seismic (SCS) ODP line 5 links Vinck-1 to Site 763. Lamont-Doherty Geological Observatory common-depth-point (CDP) multichannel seismic (MCS) reflection profile 667 (Lorenzo et al., in press) intersects ODP line 5 obliquely, and expanded spread profile C2 (ESP C2) has its midpoint centered on the MCS profile (Fig. 1, inset). Line 5 was shot with water guns while line 667 and ESP $\mathrm{C} 2$ were shot with a lower frequency airgun source.

ESP's have been used successfully to study the $V_{p}$-depth structure of passive continental margins (e.g., LASE Study Group, 1986; Mutter and Zehnder, 1988; Diebold et al., 1988; Johansen et al., 1988) through forward modeling of the primary traveltimes of seismic arrivals. Better-constrained models that also include shear wave velocity $\left(V_{s}\right)$ and $\rho$-depth information have been derived from ESP's from the deep ocean basins by additional full waveform modeling (e.g., Mithal and Mutter, 1989; Harding et al., 1989; Vera et al., 1990). For the first time, in order to establish the practical accuracy of ESP analyses, we attempt to compare a model for $V_{p}$ and $\rho$ vs. depth obtained from traveltime and 


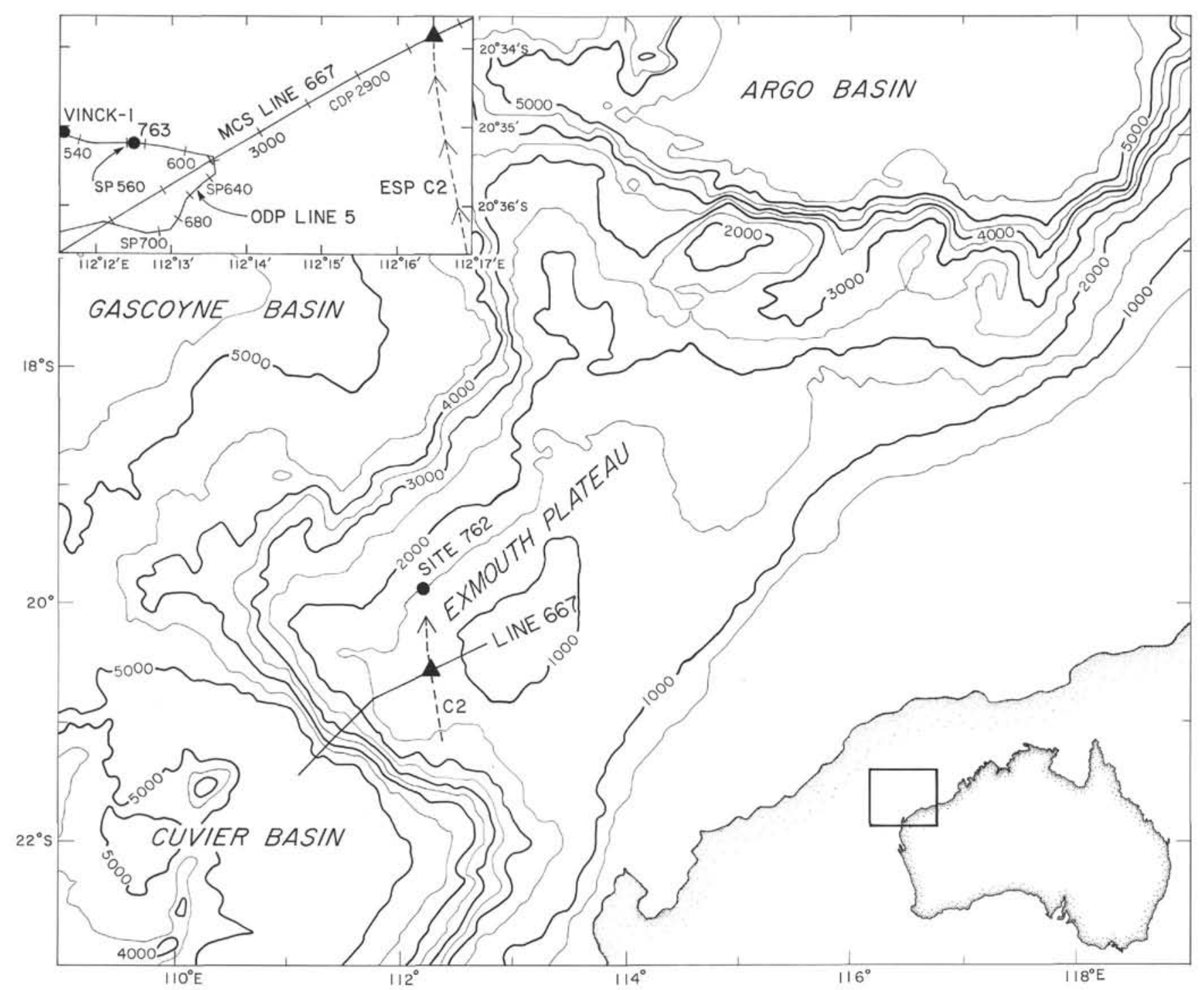

Figure 1. Bathymetric map of Exmouth Plateau, Northwest Australia; isobaths in meters. Ship track for CDP multichannel seismic (MCS) line 667 (straight continuous line) crosses southern boundary of plateau. Ship track for ESP C2 (dashed line) was shot almost at right angles to line 667. Arrow indicates direction of shooting ship during ESP experiment. Receiving ship moved southward along same track. Inset shows region around crossing of line 667 and line of ESP C2. Ship track of single-channel seismic (SCS) ODP line 5, joins ODP Site 763 to commercial well Vinck-1 (dots).

waveform modeling, to the physical properties structure derived from a scientific well. In what follows we derive a model for $V_{p}, V_{s}, \rho$, and attenuation from ESP C2. We compare this model with the shipboard and downhole physical properties values to ascertain the accuracy of the ESP analysis. Finally, MCS, SCS, and major ESP seismic reflected arrivals are paired with geologic unit boundaries with the aid of synthetic seismograms and reflection coefficient series, constructed using the physical properties values from Site 763.

\section{MAJOR SEISMIC REFLECTION HORIZONS}

In spite of the differences in reflection strength and character, and seismic resolution that affect the profiles of MCS line 667 and ODP SCS line 5 in Figure 2, three common prominent seismic horizons/reflective bands are apparent. The horizons can be interpreted tentatively from other published and interpreted reflection profiles (Exon and Willcox, 1980; Haq et al., 1988,
1990). We will refer to them and their equivalent geological intervals, using letters. From top to bottom they include reflectors: "e" ( $\sim 2.25 \mathrm{~s}$ of two-way traveltime (s TWT)) believed to indicate the Cenomanian/Turonian boundary, "f'" $(\sim 2.4 \mathrm{~s}$ TWT) near a breakup unconformity, and " $g$ "' $(\sim 3.15 \mathrm{~s}$ TWT $)$ at the roof of the Triassic pre-rift basement.

Above "e," another laterally continuous reflector, "b,"' is visible in the MCS profile and may possibly tie to the SCS profile at $2.05 \mathrm{~s}$ TWT. A set of notable high amplitude reflectors also appear at a depth of about $8 \mathrm{~km}$, below the reach of any present wells. Deep seismic crustal studies conclude that these reflectors correspond to detachment surfaces developed during rifting of the southern margin (Mutter et al., 1989; Lorenzo et al., in press).

ODP SCS line 5 was acquired using two 80 -in. ${ }^{3}$ waterguns, fired every $12 \mathrm{~s}$, or equivalently, every $30 \mathrm{~m}$ of ships' track at a nominal speed of $9 \mathrm{~km} / \mathrm{hr}$ (Haq, von Rad, O'Connell, et al., 1990). Although the MCS airgun array emitted more power 


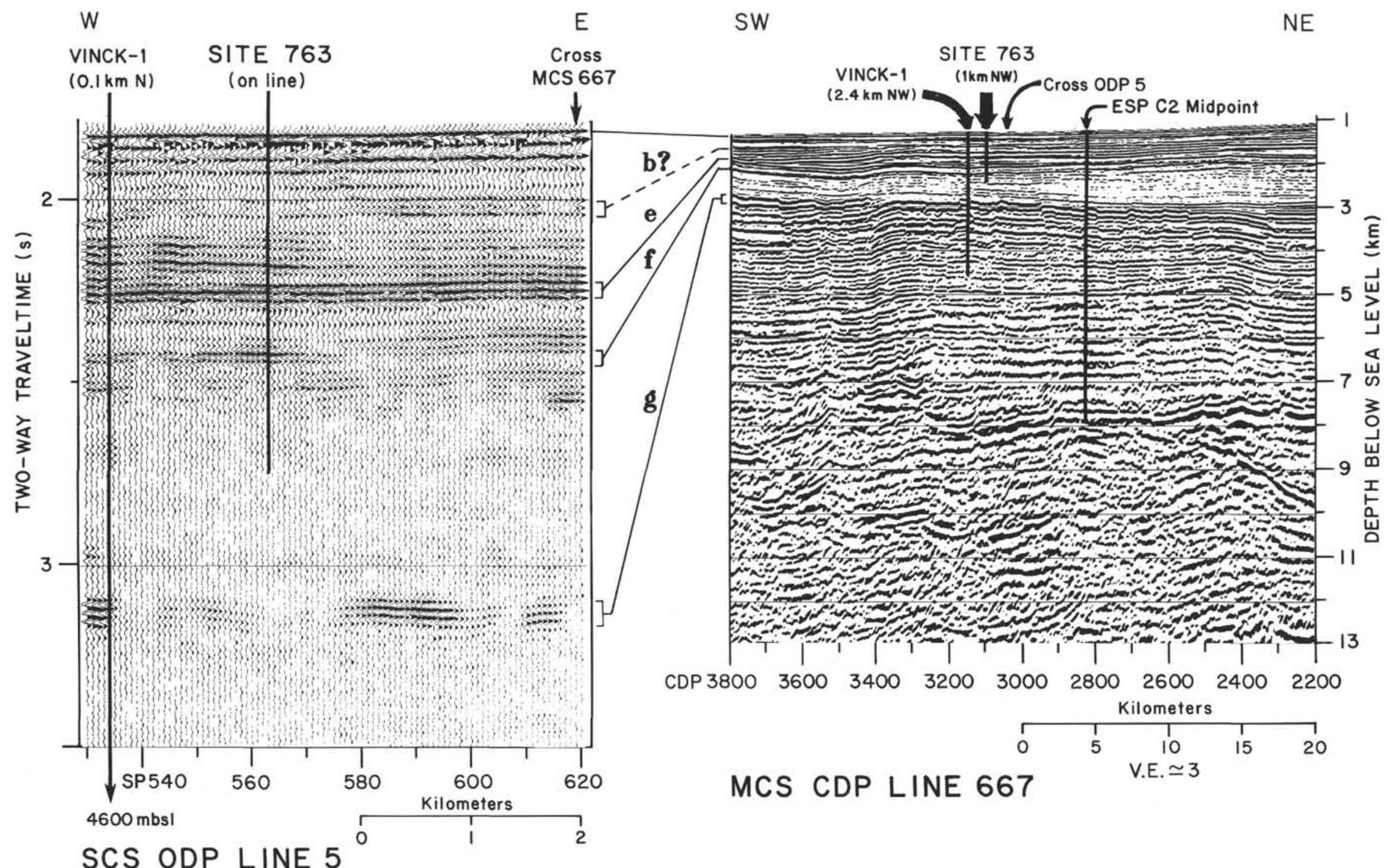

Figure 2. Regionally significant reflective zones in ODP SCS line 5 compared with MCS CDP line 667 data. Projected and online well-locations and intersections between seismic lines are superimposed. Letters mark prominent horizons; mbsl indicates meters below sea level. 
and was able to image deeper horizons it was only fired at 60 $\mathrm{s}$ intervals (or $150 \mathrm{~m}$ ). In addition, the airguns produce an oscillating bubble pulse that contaminates the data. The MCS data, which were recorded by a 48-channel hydrophone streamer towed by the Conrad, do, however, provide greater fold. Seven-fold CDP gathers were stacked to suppress laterally incoherent noise by a factor of about 2.5 over the SCS data.

\section{ESP C2}

\section{ESP Acquisition and Reduction}

An ESP experiment is a multiple-fold wide-angle reflection/ refraction data set collected using two ships, one recording and the other shooting (Stoffa and Buhl, 1979). Both vessels move away from ("'separating ranges") or toward each other ("closing ranges") at a constant speed maintaining a common fixed central reference point, to which derived seismic models are referred. The common midpoint geometry is maintained throughout the experiment to diminish the adverse effects of dipping seismic layers along the profile (Diebold and Stoffa, 1981). ESP C2 was also positioned along a track that had negligible ocean-bottom topography and was parallel to the strike of the basement structure (Exon and Willcox, 1980), to minimize the effect from dipping horizons.

Conrad acted as the shooting ship towing a tuned 10 airgun array (Diebold, 1987), centered about $60 \mathrm{~m}$ behind the ship and dipping $15^{\circ}-20^{\circ}$; the farthest guns lying deepest in the water (Fig. 3). The total airgun volume was 5821 in. $^{3}$, and the guns were fired regularly every $60 \mathrm{~s}$ at a pressure of 1800 p.s.i. Since the separation rate between the two ships was about 18 $\mathrm{km} / \mathrm{hr}$, the source-receiver range increment between shots was $300 \mathrm{~m}$. The same airgun array was used to shoot the MCS CDP profile of line 667 .

Rig Seismic of the Australian Bureau of Mineral Resources towed a 48 -channel streamer with a $50-\mathrm{m}$ group interval; the first receiving channel lay $375 \mathrm{~m}$ behind the ship. 32-s long seismograms were digitized by a nonstandard "Phoenix" recording system at a sampling rate of $4 \mathrm{~ms}$ with an anti-alias filter applied at $62.5 \mathrm{~Hz}$ tapering to a full cut-out at $125 \mathrm{~Hz}$, the Nyquist frequency.

After an initial demultiplexing, the ESP shot traces were gathered into $50-\mathrm{m}$ common-offset bins. Traces within the binning window were stacked along $x-t$ paths with slopes of 8 $\mathrm{km} / \mathrm{s}$, chosen to minimize the attenuation of high frequencies (See Appendix A). Under ideal conditions, stacking can

(TOP VIEW OF AIRGUN ARRAY)
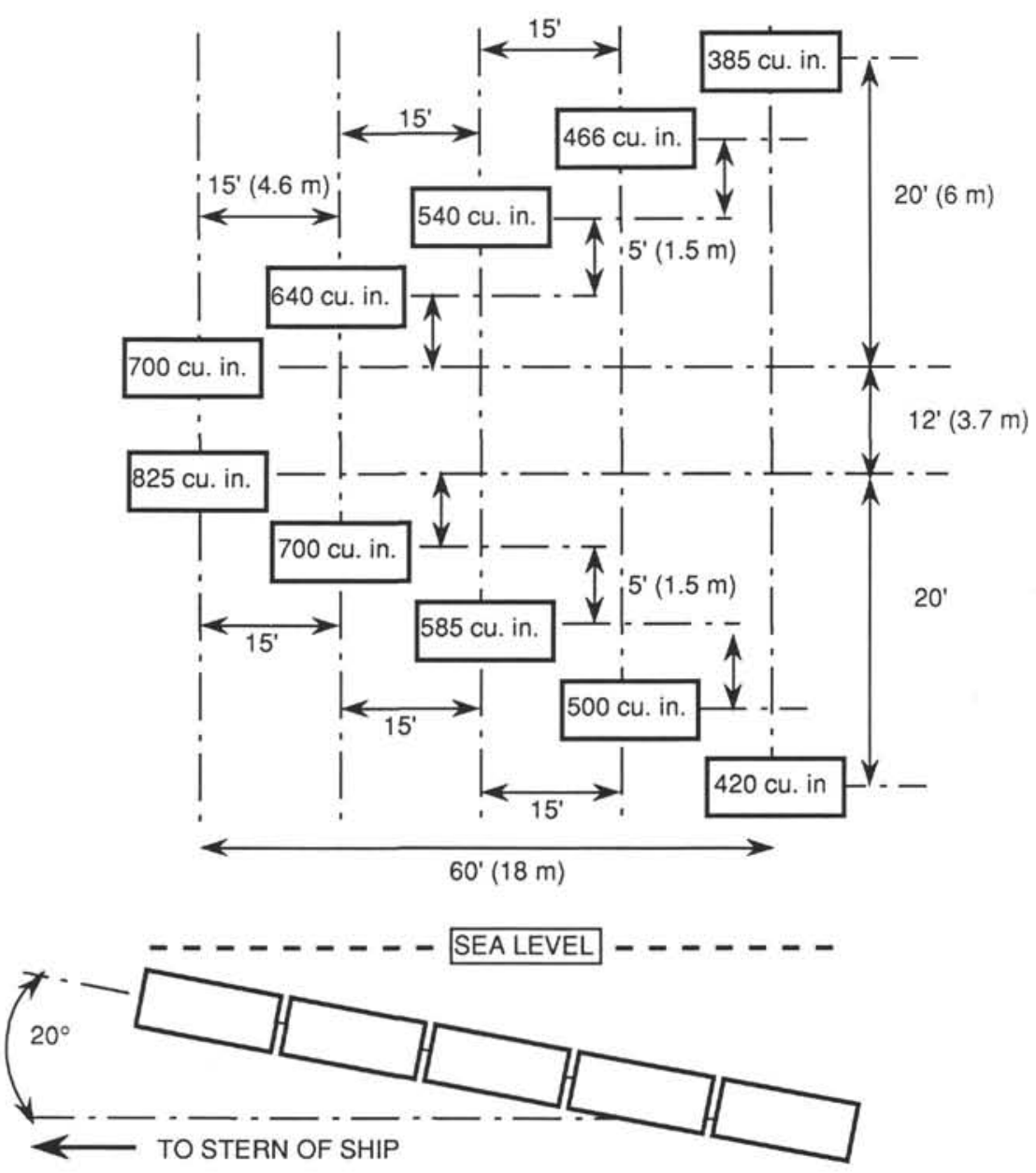

(SIDE VIEW OF AIRGUN ARRAY)

Figure 3. Approximate distribution of airguns (boxes) and their chamber volume in array used to acquire ESP C2 and MCS line 667. 
enhance the signal-to-noise ratio by a factor equal to the square root of the fold (Mayne, 1962; Robinson, 1970; Sengbush, 1983). ESP folds are between 7 and 9 for most of the ESP so that the signal-to-noise ratio could be enhanced by as much as a factor of 3 .

Errors inherent in the data acquisition that contribute to mismatches between seismic arrivals can be mostly attributed to, by order of decreasing importance, differences in the two ships' clocks, inaccuracies in the source-to-receiver ranges, and unaccounted feathering problems. The feathering angle quantifies the deviation between the path of the streamer and the ship.

In order to correct for instrument malfunctions and differential drift between ships' clocks, radio checks were sent to the Conrad on the minute of the Rig Seismic clock. Thus, we discovered and adequately corrected drift of $40 \mathrm{~ms}$ during the experiment and several discrete time jumps as large as 4-20 min.

Ship-to-ship antennae offsets were estimated by a Raydist ranging system for distances greater than $20 \mathrm{~km}$. Error in ships' ranges from Raydist is inappreciable (less that $5 \mathrm{~m}$ ) even at $100 \mathrm{~km}$ (Stoffa and Buhl, 1979). For offsets less that 20 $\mathrm{km}$, a Miniranger system was used because of its greater accuracy and precision at these distances.

Source-receiver offsets, for most of the ESP experiment geometry, were obtained by assuming the ship and streamer paths were aligned with each other. As ship-to-ship ranges decrease from about $12-15 \mathrm{~km}$ to the midpoint, sourcereceiver offsets become more sensitive to the streamer position. Without corrections for these geometric effects, arrival times are incorrect. In anticipation of this problem, the streamer geometry was monitored from the recording ship by taking radar bearings on a radar-reflecting buoy towed at the tail of the streamer. As well, visual ship-to-ship compass bearings were made as the ships crossed each other at the midpoint. After incorporating the bearings into the reduction, any residual shifts in the data were attributed to inaccurate streamer angles. These shifts were corrected, where possible, through trial and error by linearly moving out the low-velocity direct wave arrival (assuming a water velocity of $1535 \mathrm{~m} / \mathrm{s}$ ) which was a sensitive indicator changes in the streamer-toship angles. Hyperbolic moveout reduction for the sea-bottom reflection was also used to correct residual shifts where the direct water wave at farther ranges was not available.

\section{ESP Analytical Techniques}

ESP C2 in Figure 4 (top diagram) displays minimal observable topographic effects. Both the closing and separating halves of the experiment produce similar arrivals; herein we analyze only the separating side in detail.

An initial $V_{p}$-vs.-depth model was constructed using the " $\tau$-sum" recursion technique of Diebold and Stoffa (1981). For this purpose, the data were first transformed from the offset-traveltime domain $(x-t)$ into the domain of intercept time-ray parameter $(\tau-p)$ by slant stacking (Stoffa et al., 1981). In addition, corrections were applied to account for geometric spreading and phase shifts. By this we achieved a plane-wave decomposition (Mithal and Vera, 1987) (Fig. 5, top diagram). Once in the $\tau-p$ domain, discrete first-break picks were made on the post-critical arrivals, at velocity $(1 / p)$ increments as consistently close as possible to $50 \mathrm{~m} / \mathrm{s}$ and an intercept time resolvable to less than the $4 \mathrm{~ms}$ sample interval ( $3 \mathrm{~ms})$.

We found that the starting $V_{p}$-depth model (Fig. 6B) could be simplified by using fewer gradient and constant velocity layers. The modified model was still able to match the primary arrival times of the principal events in $x-t$.
Ray theory amplitude modeling and full waveform modeling of the ESP data employed a source wavelet extracted from the seafloor reflection in the nearest vertical trace $(p \sim 0)$, comprising the primary seafloor pulses and up to and including the first bubble pulse (Fig. 4, inset). We bandpass-filtered both the data that were modeled and the source wavelet used in modeling, between 0 and $20 \mathrm{~Hz}$ with a high cosine taper width of $15 \mathrm{~Hz}$. The filter was designed to preserve the dominant frequencies in the airgun source while substantially reducing background noise. Stacking and binning effects are also advantageously minimized at these low frequencies (see Appen$\operatorname{dix}$ A).

Beginning with the seafloor reflection branches and continuing downward, the amplitude-vs.-offset decay patterns of the pre-critical reflections were matched by ray theory amplitude modeling. At this stage, $\rho$ and $V_{s}$ values were incorporated into the model. Starting $\rho$ values were derived using empirical relationships between $V_{p}$ and $\rho$ for silt and carbonate sediments (Gardner et al., 1974; Hamilton, 1976). Starting $V_{s}$ values were estimated from a relationship of $V_{p} / V_{s} \sim 2$. Model parameters $V_{p}, V_{s}$, and $\rho$ were iteratively changed until post-critical amplitudes and waveforms calculated using the WKBJ method (Chapman, 1978) matched the $x-t$ data. We found that during ray theory amplitude modeling, an individual change of less than $10 \%-15 \%$ in the values for $V_{p}, V_{s}$, and $\rho$ does not significantly alter the best match of the offset-amplitude decay pattern. When we imposed traveltime constraints, the precision of these values appeared doubled.

Further modeling matched computed full-reflectivity seismograms, in the $x-t$ domain (Fig. 4 , bottom diagram) and the $\tau-p$ domain (Fig. 5, bottom diagram). Full-reflectivity considers all possible internal multiples and energy losses due to transmissivity, geometric spreading, and attenuation (Appendix B). Parameters $V_{p}, V_{s}$, and $\rho$ for the final best-matching model are shown in Table 1 . We used a quality factor $\left(Q_{p}\right) \sim$ 500 when calculating attenuation effects throughout the model. This value is about one order of magnitude larger than estimated by O'Brien and Manghnani (this volume). Their $Q_{p}$ was measured using a $1 \mathrm{Mhz}$ acoustic source. Over the useful range of frequencies in our source, $6-45 \mathrm{~Hz}$, internal friction and, hence, attenuation in rocks is much smaller (i.e., $Q_{p}$ larger) than at higher frequencies and can be considered as effectively constant (Knopoff, 1964; Liu et al., 1976). The $S$-wave quality factor $\left(Q_{s}\right)$ was generated from $Q_{p}$ assuming that there is much less dilatation in volume than in shear deformation (Müller, 1985).

Particular care was also taken to forward model the high amplitude waveforms in the nearest-offset trace. Because the ratio of water depth to the first offset distance is large, about $5: 1$, we were able to assume conditions of normal incidence and use the "acoustic case" approximation of the full-reflectivity method to calculate normal incidence seismograms.

Contained in the source wavelet used, are several p-dependent "ghosts" or seismic pulses produced from reflections at the sea-surface near the source and receiver (Parkes and Hatton, 1986). We, however, used the same wavelet at all values of $p$. The amplitude of "ghosts" and of most of the seismic wavelet are more severely attenuated at higher $p$ 's and can be expressed as a function of frequency and $p$ (see Appendix A). As seen in the top diagram of Figure 5, at a $p$ of about $0.6 \mathrm{~s} / \mathrm{km}$, the observed seismic arrivals are very weak, although in the synthetic seismograms of the diagram below the computed amplitudes are stronger. To compensate for this effect of attenuation due to ghosting, the reflectivity calculation of the ESP seismograms in the $x-t$ domain we considered only $p$ values less than about $0.6 \mathrm{~s} / \mathrm{km}$ (Fig. 5). Thus, a 

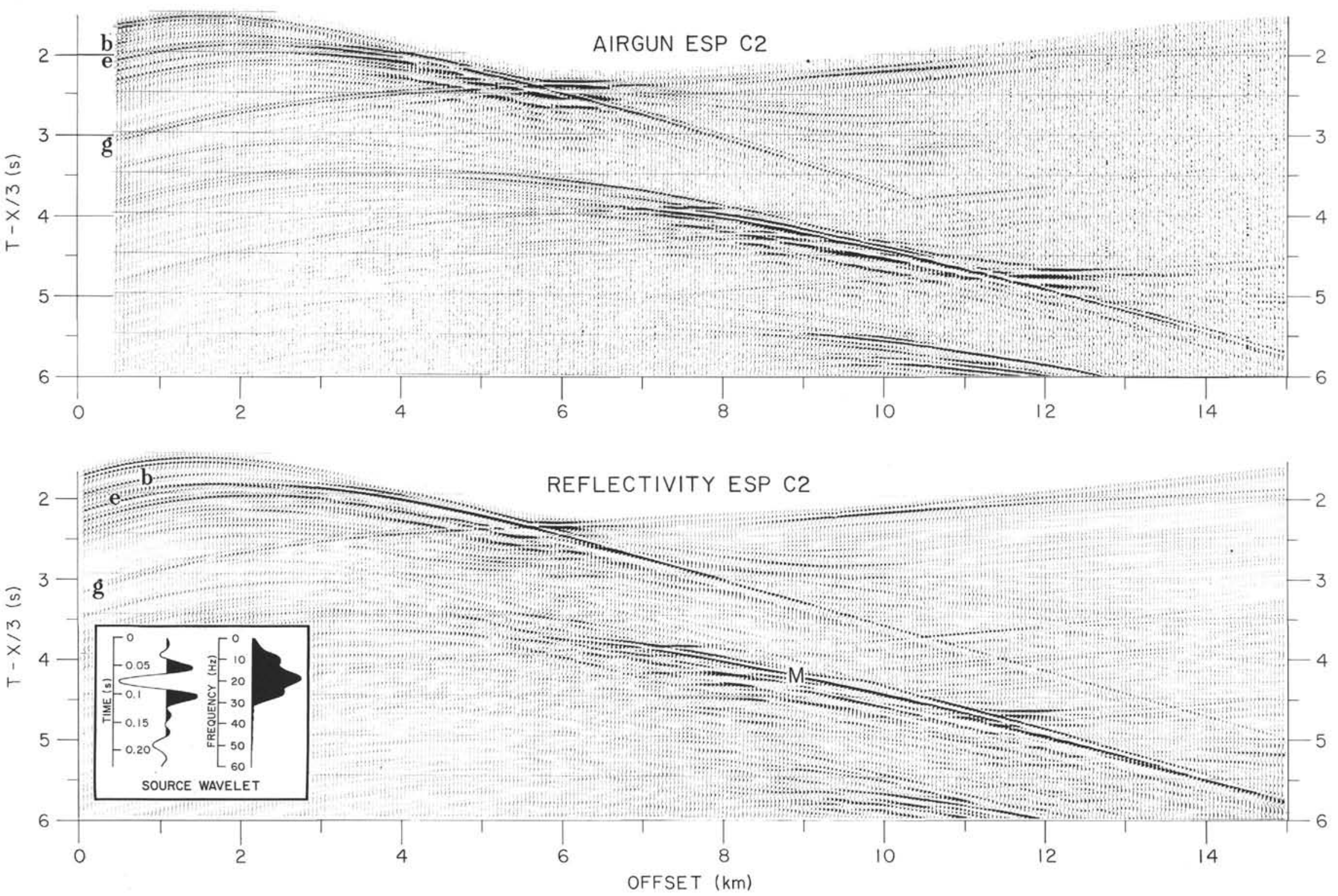

Figure 4. ESP C2 seismic data (top diagram) and reflectivity model (bottom) in domain of receiver-source offset-traveltime ( $x-t$ ). Linear reduction of $3 \mathrm{~km} / \mathrm{s}$ has been applied to reduce arrivals that have phase velocity of $3 \mathrm{~km} / \mathrm{s}$ to horizontal. Seafloor reflection pulse of model at $p=0$ is normalized to data for direct comparison. "M" lies on first seafloor multiple reflection. Estimated seismic source wavelet (inset) was used to calculate full-reflectivity model. 


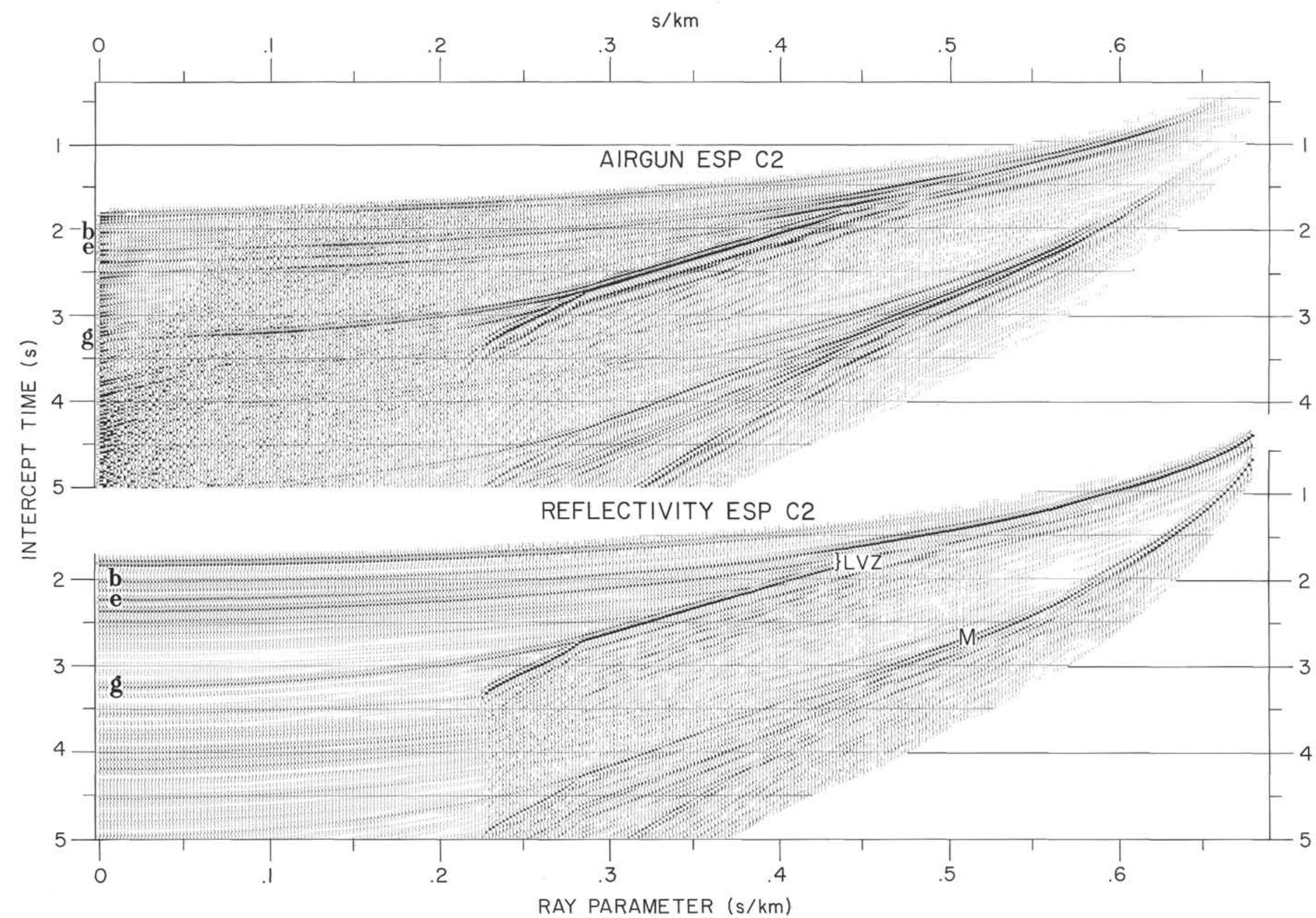

Figure 5. ESP seismic data (top diagram) of Figure 4, transformed into $\tau-p$ domain by plane-wave decomposition; $p$ increases by $0.002 \mathrm{~s} / \mathrm{km}$ in seismograms. Seafloor reflection pulse is normalized to data for direct comparison. 


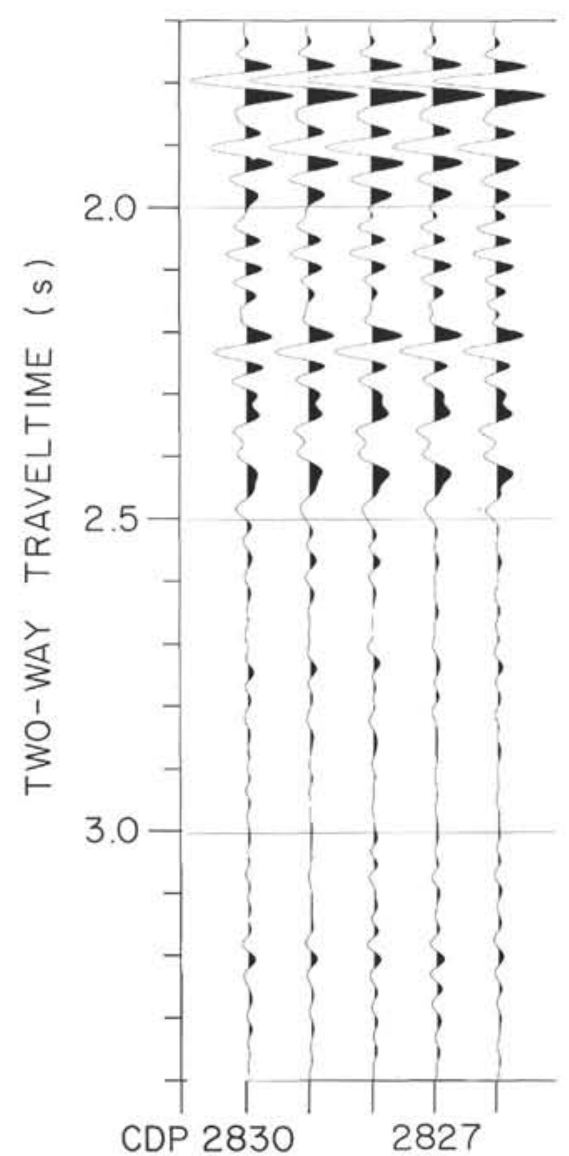

A

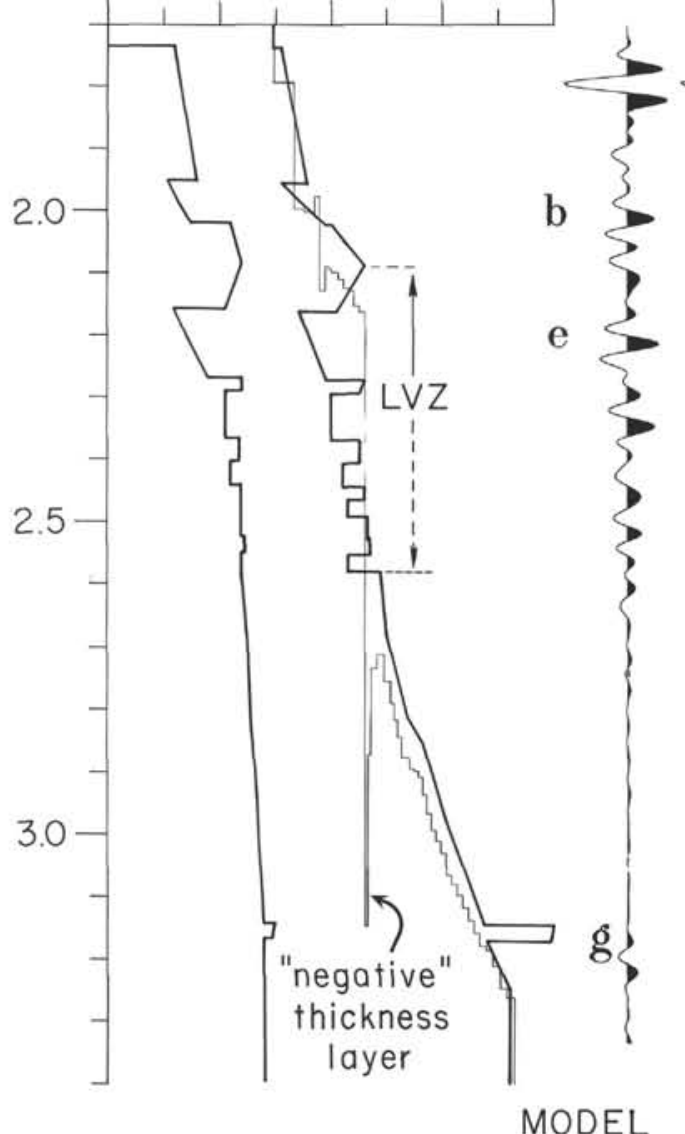

B
ESP C2

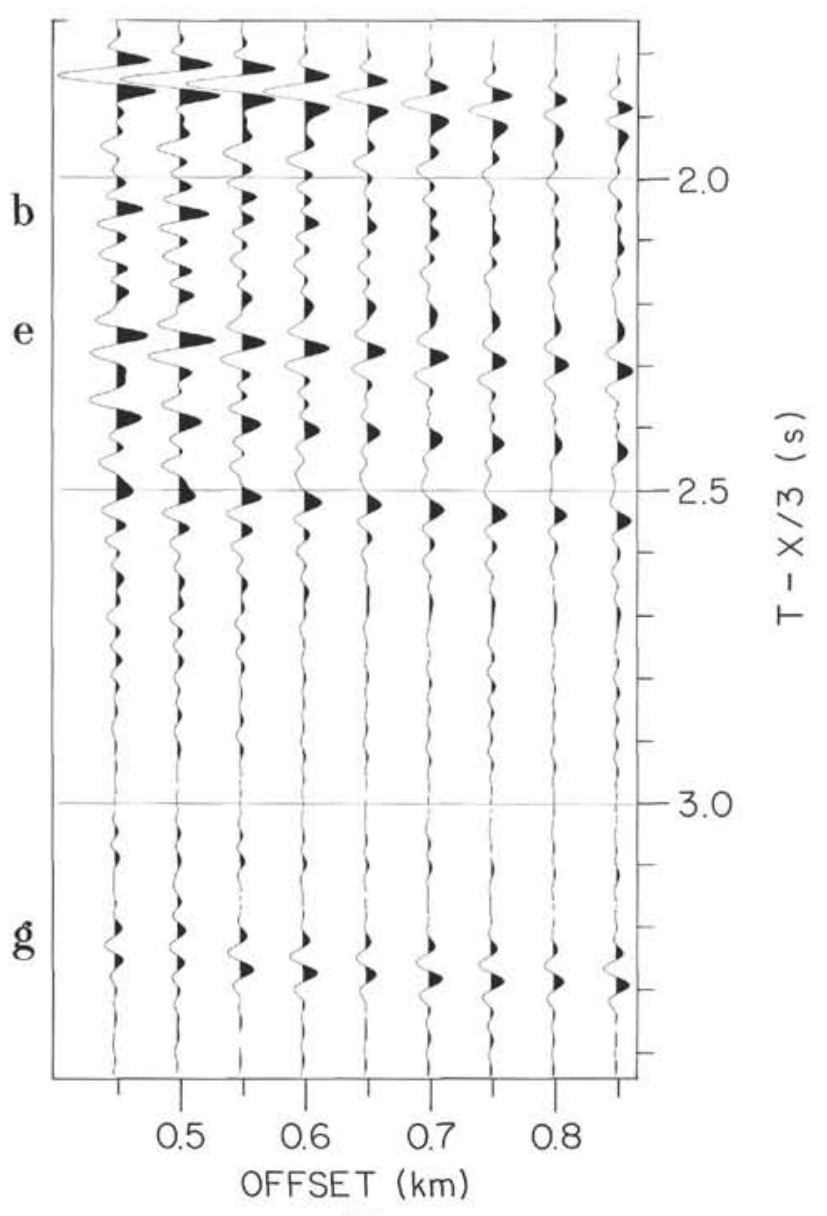

D

Figure 6. Comparison between normal incidence reflection seismic data, ESP data and synthetic seismograms, all bandpass-filtered between 0 and $20 \mathrm{~Hz}$, with high cosine taper of width $15 \mathrm{~Hz}$. A. CDP seismograms. B. $V_{p} / \rho$-vs.-depth models (thick lines) used to generate synthetic $x-t$ and $\tau-p$ seismograms of preceding figures. Initial starting model (thin line of $V_{p}$ vs. depth) was derived using " $\tau$-sum" construction technique of Diebold and Stoffa (1981). C. On left, full-reflectivity seismogram calculated for normal incidence conditions from best ESP C2 model, and on right, nearest-offset trace from ESP C2. D. First nine seismograms from ESP C2 data, seen in top diagram of Figure 5. 
Table 1. Values of physical parameters shown in Figure 5, representing the seismic model constructed from ESP data of Figures 3 and 4.

\begin{tabular}{|c|c|c|c|c|c|}
\hline $\begin{array}{l}\text { Depth } \\
\text { (mbsl) }\end{array}$ & $\begin{array}{c}\text { Two-way } \\
\text { traveltime } \\
\text { (s) }\end{array}$ & $\begin{array}{c}V_{p} \\
(\mathrm{~km} / \mathrm{s})\end{array}$ & $\begin{array}{c}V_{s} \\
(\mathrm{~km} / \mathrm{s})\end{array}$ & $\underset{\left(\mathrm{g} / \mathrm{cm}^{3}\right)}{\rho}$ & Reflector \\
\hline 1287 & 1.737 & 1.482 & 0 & 1.0 & \\
\hline 1466 & 1.953 & $1.550 / 1.775$ & 0.8 & $1.6 / 1.8$ & \\
\hline 1526 & 2.021 & $1.55 / 1.95$ & $0.5 / 0.9$ & $1.55 / 1.75$ & "b" \\
\hline 1596 & 2.087 & $2.0 / 2.3$ & $1.0 / 0.95$ & $2.1 / 2.2$ & \\
\hline 1676 & 2.160 & $2.3 / 2.05$ & $0.95 / 1.0$ & $2.2 / 2.05$ & \\
\hline 1776 & 2.270 & $1.7 / 1.95$ & $0.65 / 0.9$ & $1.6 / 1.9$ & "e" \\
\hline 1801 & 2.292 & $2.3 / 2.25$ & 1.1 & 2.2 & \\
\hline 1876 & 2.367 & 2.0 & 0.95 & 2.05 & \\
\hline 1916 & 2.403 & 2.25 & 1.1 & 2.175 & \\
\hline 1956 & 2.441 & 2.1 & 0.95 & 2.1 & \\
\hline 1981 & 2.462 & 2.3 & 1.15 & 2.2 & \\
\hline 2011 & 2.490 & 2.15 & 0.95 & 2.2 & \\
\hline 2051 & 2.525 & 2.325 & 1.175 & 2.2 & \\
\hline 2081 & 2.550 & 2.35 & 1.18 & 2.22 & \\
\hline 2111 & 2.578 & 2.15 & 1.0 & 2.2 & \\
\hline 2229 & 2.674 & $2.445 / 2.497$ & 1.3 & $2.2 / 2.25$ & \\
\hline 2405 & 2.809 & $2.497 / 2.688$ & $1.3 / 1.4$ & $2.25 / 2.275$ & \\
\hline 2460 & 2.849 & $2.688 / 2.813$ & $1.4 / 1.5$ & $2.275 / 2.3$ & \\
\hline 2623 & 2.962 & $2.813 / 3.0$ & $1.5 / 1.6$ & $2.3 / 2.35$ & \\
\hline 2913 & 3.144 & $3.0 / 3.375$ & $1.6 / 1.7$ & $2.35 / 2.4$ & \\
\hline 2963 & 3.169 & $4.0 / 3.975$ & 1.9 & $2.5 / 2.48$ & "g" \\
\hline 3098 & 3.246 & $3.4 / 3.6$ & $1.7 / 1.8$ & $2.4 / 2.41$ & \\
\hline 3481 & 3.459 & $3.6 / 3.608$ & 1.8 & 2.41 & \\
\hline 3735 & 3.596 & $3.608 / 3.778$ & $1.8 / 1.85$ & $2.41 / 2.425$ & \\
\hline 3835 & 3.648 & $3.778 / 3.927$ & $1.85 / 1.95$ & $2.425 / 2.453$ & \\
\hline 3851 & 3.656 & $3.927 / 3.977$ & 1.95 & 2.453 & \\
\hline 4346 & 3.893 & $3.977 / 4.409$ & $1.95 / 2.2$ & $2.453 / 2.52$ & \\
\hline 5246 & 4.297 & $4.409 / 4.5$ & 2.2 & $2.52 / 2.58$ & \\
\hline
\end{tabular}

Note: A quality factor of $Q_{p}=500$ was used for all layers in the model.

comparatively good match was achieved in the $x-t$ domain for the amplitudes in the far-offset seafloor reflections (Fig. 4).

\section{Principal ESP Arrivals}

Many major reflection branches in the $x-t$ data arise from the top interfaces of low-velocity/density zones (LVZ's). These reflections can also be tied to their homologues in the CDP data of line 667 at the ESP midpoint (Fig. 6). We denote the reflection branches descriptively using letter names which we later show correspond to significant geological boundaries.

At normal incidence, "b" and "e," produced in the uppermost sediments, appear $180^{\circ}$ phase shifted with respect to the seafloor reflection (Fig. 6). A $180^{\circ}$ phase shift in the waveform can be produced by the negative impedance contrast at the top of a LVZ. According to classical ray theory, LVZ's cannot refract rays upward. Instead, rays turn upward on exiting the LVZ, that is, where $p$ is equal to or less than upon entering. In our particular velocity model, $p$ is equal on entering and leaving the LVZ so that only a gap in $\tau$ is expected. Such a gap is visible in the $\tau-p$ data set (Fig. 5) below the intersection of the reflection branch from " $e$ " and the underlying branch of post-critically refracted arrivals. The " $\tau$-sum" construction (Fig. 6) contains layers of negative thickness at $2.1 \mathrm{~s}$ TWT and $3.1 \mathrm{~s}$ TWT. These negative thickness layers are artifacts of the technique when applied to LVZ's (Diebold, 1980; Vera, 1987; Diebold, 1989).

Within the LVZ below "e" (Fig. 6B), the layered structure was derived by comparing reflections at normal incidence to those calculated using full-reflectivity. We started by simply assuming a single-gradient velocity structure for the LVZ. We constructed layers that followed this trend while adjusting $V_{p}$, $V_{s}$, and $\rho$ to best fit the observed traveltimes and waveforms at normal incidence. The resulting synthetic seismogram matches the data very well (Fig. 6C).
Below reflection "g," the LVZ is approximately $900 \mathrm{~m}$ thick (see Table 1), about 3 times greater than below "e." Here, however, the $\tau$-sum construction does not produce corresponding negative layers and a $\tau-p$ data gap, as was produced by reflection " $e$," is not observed. The phenomenon cannot be explained by ray theory that only considers ray paths at infinitely high frequencies. For real rays and hence for the finite frequencies of our seismic source, there is an exponential decay of energy below every turning point. In the case of the LVZ below "g," the high velocity lid is thin enough for most of the energy to leak into the LVZ without much attenuation over the frequency range of our source. Once in the LVZ, our particular velocity structure is such that rays are refracted upward without a loss of continuity in $p$ in the arrivals. The general phenomenon is known as "wave tunneling" by analogy to a similar effect in quantum mechanics (Aki and Richards, 1980, p. 445; Bullen and Bolt, 1987, p. 192).

Reflection " $g$ " and its extension into the pre- and postcritical reflection branches is best analyzed as a very thin ( 50 m) high velocity layer $(\sim 4 \mathrm{~km} / \mathrm{s})$. Calculations using ray theory predict the amplitude of " $g$ " would be half as large as with full-reflectivity theory. According to ray theory, unreasonably large $V_{p}$ and $\rho$ contrasts would be required to match the observed amplitudes. We can more simply attribute the large amplitudes to the constructive interference of returning reflections (e.g., Widess, 1973); a phenomenon known as reflection "tuning." The thickness of the layer producing " $\mathrm{g}$ " is such that for the estimated airgun seismic source (Fig. 4), the reflections from its top and base (with a reversed polarity), interfere constructively doubling the expected amplitude. On the other hand, in the $\tau-p$ domain (Fig. 5), the reflected arrivals from the top and bottom of this "ledge" in the velocity-depth plot, merge near the critical point and thus the layer thickness cannot be distinctly resolved. For a dominant source frequency of $20 \mathrm{~Hz}$, this layer is about one-fourth wavelength thick $(\sim 50 \mathrm{~m})$, at the practical limit of resolution.

\section{COMPARISON OF PHYSICAL PROPERTIES DATA WITH ESP MODEL}

Using a relatively simple model (Table 1 and Fig. 6B), we have been able to match the traveltime and waveforms of the most significant arrivals in ESP C2 (Fig. 4). The downhole long-spaced sonic tool used at Site 763 and the shipboard velocimeter provide closely spaced measurements at least every few meters. Their sound sources emit frequencies that are 3-5 orders of magnitude higher than the airgun array which was used to shoot ESP C2. Therefore, the ESP-derived model is expected to provide the larger-scale trends in $V_{p}$ and $\rho$ with depth.

\section{Physical Properties Data Reduction}

Shipboard physical properties measurements are subject to instrument errors and sample rebound effects. In a comparison of shore-based physical properties with the shipboard data from Site 763, O'Brien and Manghnani (this volume) conclude that shore-based density estimates are consistently greater than shipboard bulk densities because of deficiencies imposed by the pycnometer when measuring the wet-bulk density at sea. Moreover, raw shipboard bulk density measurements do not take into account rebound effects-expansion of the samples that increases their porosity above in-situ values (Hamilton, 1976).

We first corrected raw wet-bulk density values taking into account the effect of the pycnometer and sample rebound using regression equations from O'Brien and Manghnani (this volume) and Hamilton (1976), respectively. From these den- 
sities, velocities corrected to in-situ conditions were derived using empirical $V_{p}-\rho$ relationships for silts and carbonate sediments (Hamilton, 1978). The corrected data were smoothed using a 3-point running average (a 9-m window), with an output at the center of the window. Samples originating below about 600 mbsf were extensively fractured during drilling (Haq, von Rad, O'Connell, et al., 1990) and gave highly erroneous shipboard velocity estimates which we discarded.

Figure 7 displays both the raw and corrected shipboard $\rho$ and $V_{p}$ values from Site 763. Raw $V_{p}$ values underestimate traveltime to major reflectors. "Corrected" $V_{p}$ values are derived from corrected $\rho$ values with the known empirical relations (Hamilton, 1978). Both differ from the values in the ESP model by a few hundred meters per second. In this respect, the ESP-derived model may provide more accurate physical properties because it is free from instrument errors, drilling disturbances, and sample rebound effects. Indeed, one possible cause for this discrepancy may be tied to rebound effects. At Site 762, O'Brien and Manghnani (this volume) attribute an offset of $0.3 \mathrm{~km} / \mathrm{s}$ between the shipboard velocity data and the downhole sonic data to this cause. It is also possible that part of the discrepancy may be due to errors in the electronic calibration for the Hamilton Frame velocimeter (Haq, von Rad, O'Connell, et al., 1990).

Downhole $V_{p}$ data at Site 763 were collected wholly within a LVZ (below "'e") for which we can only make the simplest assumptions regarding the general velocity structure, since there are no refracted returns from this region. Hence, some of the individual model layers appear displaced in depth with respect to the borehole and shipboard physical properties data (Figs. 7 and 8).
Nevertheless, the trend of the $V_{p}$ data values from the ESP model are closer to the downhole data than the shipboard derived $V_{p}$ estimates.

Downhole $V_{p}$ measurements (sonic logs) are free of rebound effects and should agree better with the ESPderived model. They also provide regularly spaced values regardless of the percentage of core recovery. However, the downhole $V_{p}$ data set at Site 763 covers only from 406.8 and $600 \mathrm{mbsf}$ and between 657 and $708 \mathrm{mbsf}$, at regular $0.5 \mathrm{~m}$ intervals. $V_{p}$ values were resampled into 3 -m intervals for comparison with the shipboard derived physical properties measurements. Similarly, sonic tool $V_{p}$ measurements from the Vinck-1 well, $1 \mathrm{~km}$ west of Site 763 (Fig. 9B) only exist below about 400 mbsf. Vinck-1 $V_{p}$ values were digitized from sonic logs once every $2 \mathrm{~m}$, smoothed using a 5 -point running average with an output at the center of the window, and resampled at $10 \mathrm{~m}$ intervals.

\section{Origin of Major Reflections}

Site 763 physical properties plots show marked changes in the trends of $V_{p}$ and $\rho$ at the depths of major reflectors in ESP C2 (Figs. 7 and 8). The origin of the reflectors lies in the geologic history that created the strong impedance contrasts. The model parameters are better compared with the normal incidence reflection coefficient series, constructed from raw shipboard physical properties data (Fig. 7C) and downhole sonic logs using empirical estimates of $\rho$ (Hamilton, 1978; and Fig. 8B). The reflection coefficients neither consider energy losses due to transmissivity or geometric spreading, nor account for sample rebound effects, but over these small ranges of depth and velocity, they can serve as a first

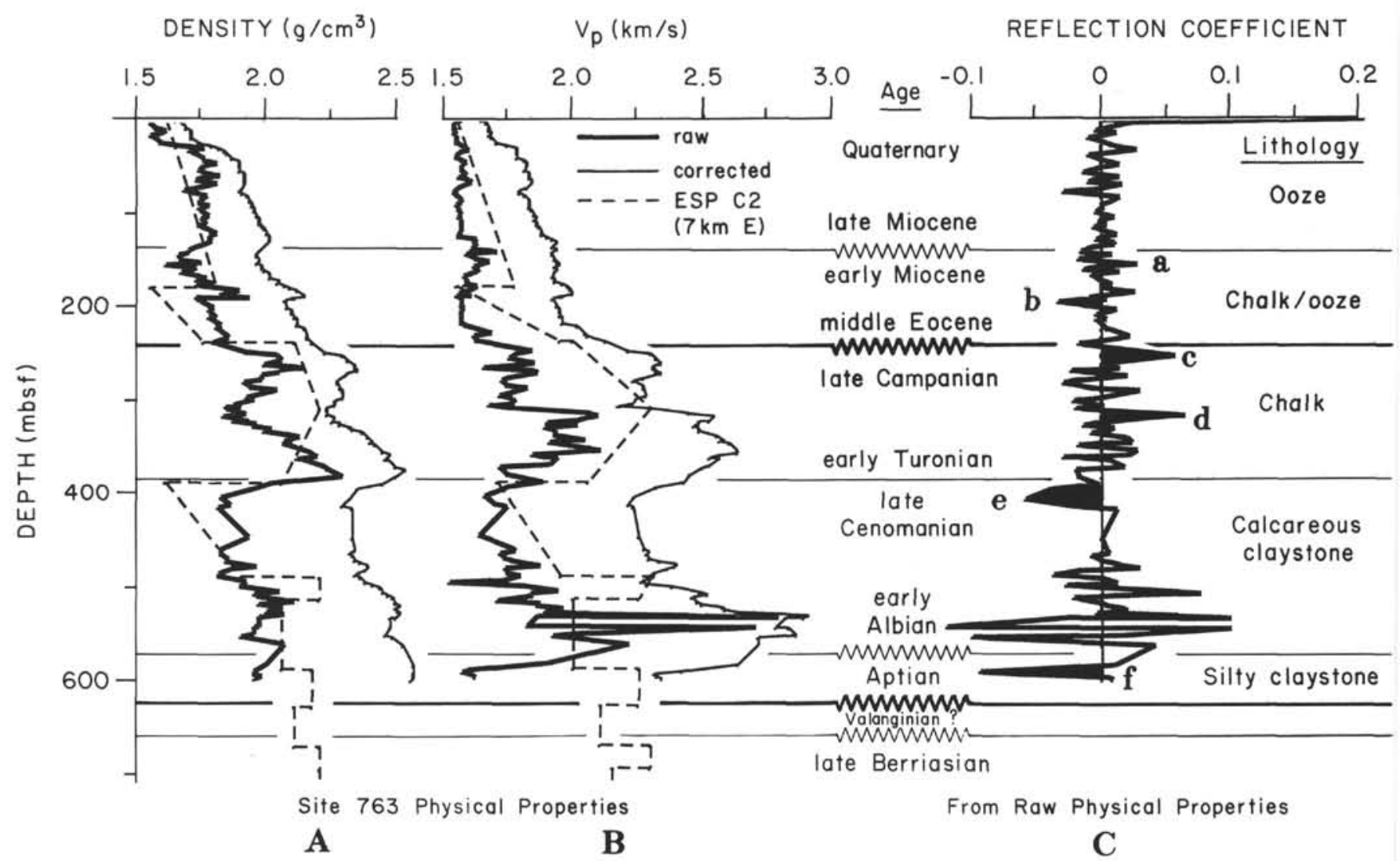

Figure 7. A. Shipboard estimates of $\rho$ vs. depth. B. Compressional wave velocity $\left(V_{p}\right)$ vs. depth in meters below seafloor (mbsf) (thick line). C. Reflection coefficient depth series calculated using raw physical properties data. Biostratigraphic and lithologic boundaries can correspond to large hiatuses (thick wiggles) or smaller ones (thin wiggles). 


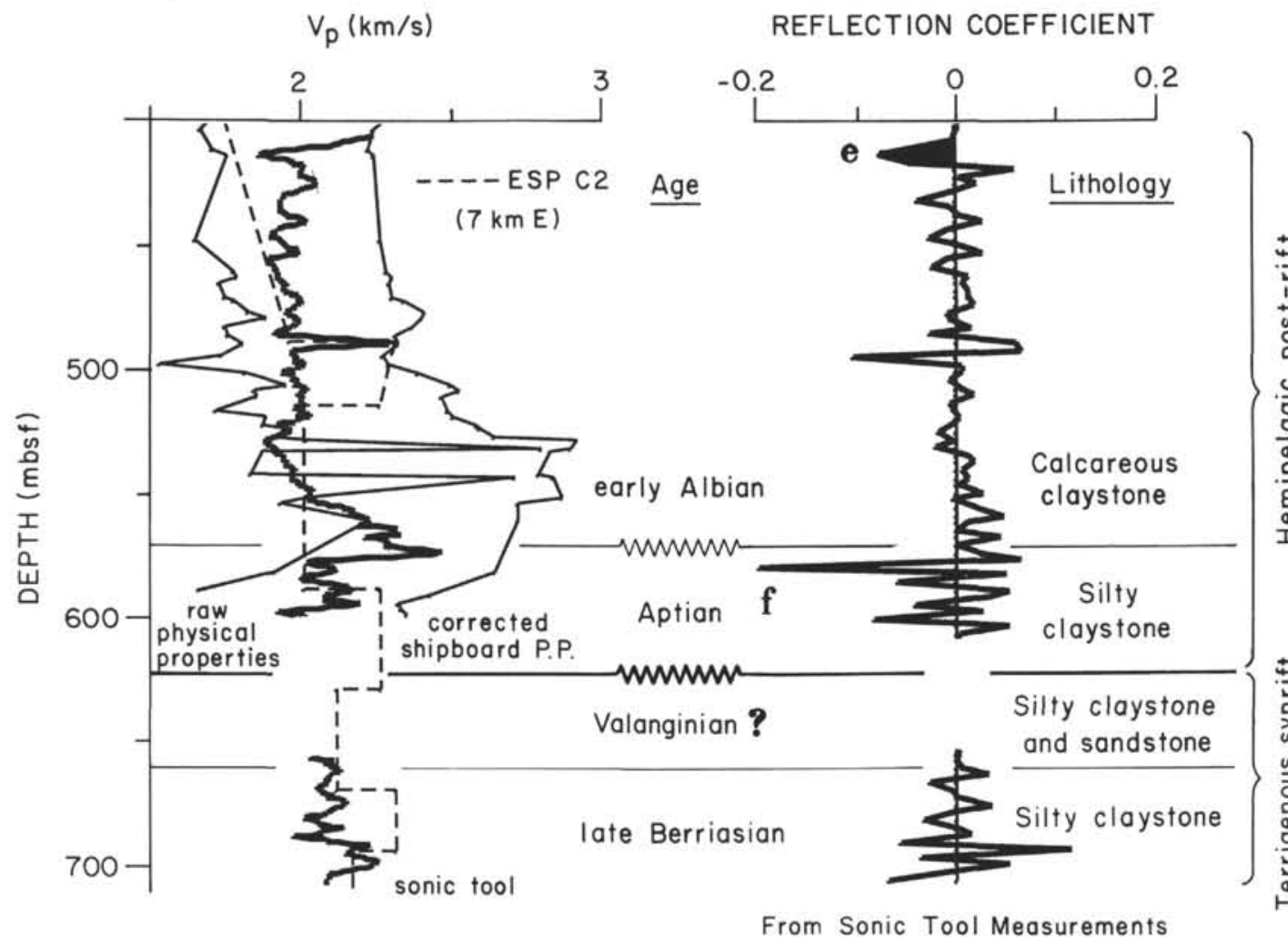

$\mathbf{A}$

B

Figure 8. A. Shipboard physical properties estimates (P.P.) of compressional wave velocity $\left(V_{p}\right)$ vs. depth (left thin line) in meters below seafloor (mbsf), also corrected for sample rebound effects and instrument errors (right thin line) and compared to downhole sonic tool data (thick line). All data are from Site 763. B. Reflection coefficient depth series calculated using sonic tool data.

approximation for estimating the relative strength of the normal incidence reflection amplitudes.

Reflector "b" is coincident with the top of a LVZ in the ESP model and in the shipboard physical properties data. Details of these properties can be found in Haq et al. (1990). The smaller $V_{p}$ and $\rho$ values in the LVZ are macroscopic parameters reflecting the greater degree of induration above "b," also expressed as a relative decrease in the water content of the sediments by $\sim 5 \%$ and an increase in the shear strength (Haq, von Rad, O'Connell, et al., 1990). At this depth, calculations suggest that in the late Oligocene, the sedimentation rate (uncompacted) changed from $\sim 6 \mathrm{~m} / \mathrm{m}$.y. below to $\sim 2 \mathrm{~m} / \mathrm{m}$.y. above " $\mathrm{b}$ " (Haq, von Rad, O'Connell, et al., 1990).

Reflector "c" occurs near the Cretaceous/Tertiary unconformity, the largest erosional hiatus drilled at Site 763 . With respect to Site 762 , it appears that $\sim 350 \mathrm{~m}$ of sediment were eroded over a $\sim 30 \mathrm{~m} . \mathrm{y}$. time interval, perhaps as a result of increase bottom-water circulation or tectonic uplift (Haq, von Rad, O'Connell, et al., 1990). This unconformity places poorly indurated chalk in contact with underlying more consolidated chalk that was probably compacted by the former load of eroded sediments.

Reflector "e" concurs in depth with the most marked LVZ in the ESP model and a regionally significant LVZ in the shipboard physical properties at approximately the Cenomanian/Turonian boundary. In this case, the negative reflection coefficient is primarily linked to a significant change in the eupelagic carbonate content in the sediments (Haq, von Rad, O'Connell, et al., 1990). The concentration of calcium carbon- ate increases from about $20 \%-50 \%$ below "e" to about $50 \%-70 \%$ above. In place of the carbonate, below " $\mathrm{e}$ " there is a much larger percentage of lower density zeolites (2.2-2.5 $\mathrm{g} / \mathrm{cm}^{3}$ ), clays, and metamorphic detrital minerals (Haq, von Rad, O'Connell, et al., 1990). There may be both local and regional causes to explain the abrupt disappearance of terrigenous sediment components at about the Cenomanian/Turonian transition. (The clastic supply came from the south or the mainland to the east.) Already, by the Hauterivian, Greater India had cleared the western end of the Exmouth Plateau (Larson et al., 1979) and therefore cannot be considered as the Cenomanian supply source. The southern transform margin, however, appears to have undergone extensive erosion during seafloor spreading in response to thermal uplift (Lorenzo et al., in press) after the Hauterivian. Perhaps erosion ceased as the southern margin subsided below wave base during the Cenomanian. The change from detrital to carbonate deposition has been recognized along all of the western Australian margin from $15^{\circ}$ to $35^{\circ} \mathrm{S}$ (Veevers and Johnstone, 1974) and therefore could be related to a generalized diminution in clastic supply.

Reflector " $f$ " occurs within a negative velocity gradient that can be attributed to a rapid decrease in the carbonate content from mid-range values $\sim 20 \%-50 \%$ in the unit above (calcareous claystone), to less than $10 \%$ in the silty claystone unit below. Reflector " $\mathrm{f}$ " occurs within a tectonically significant segment of the geologic column. At the lower boundary of this lithologic unit, the breakup unconformity divides the post-rift section above from the synrift Barremian-Valanginian(?) terrigenous sedimentary section below, deposited dur- 


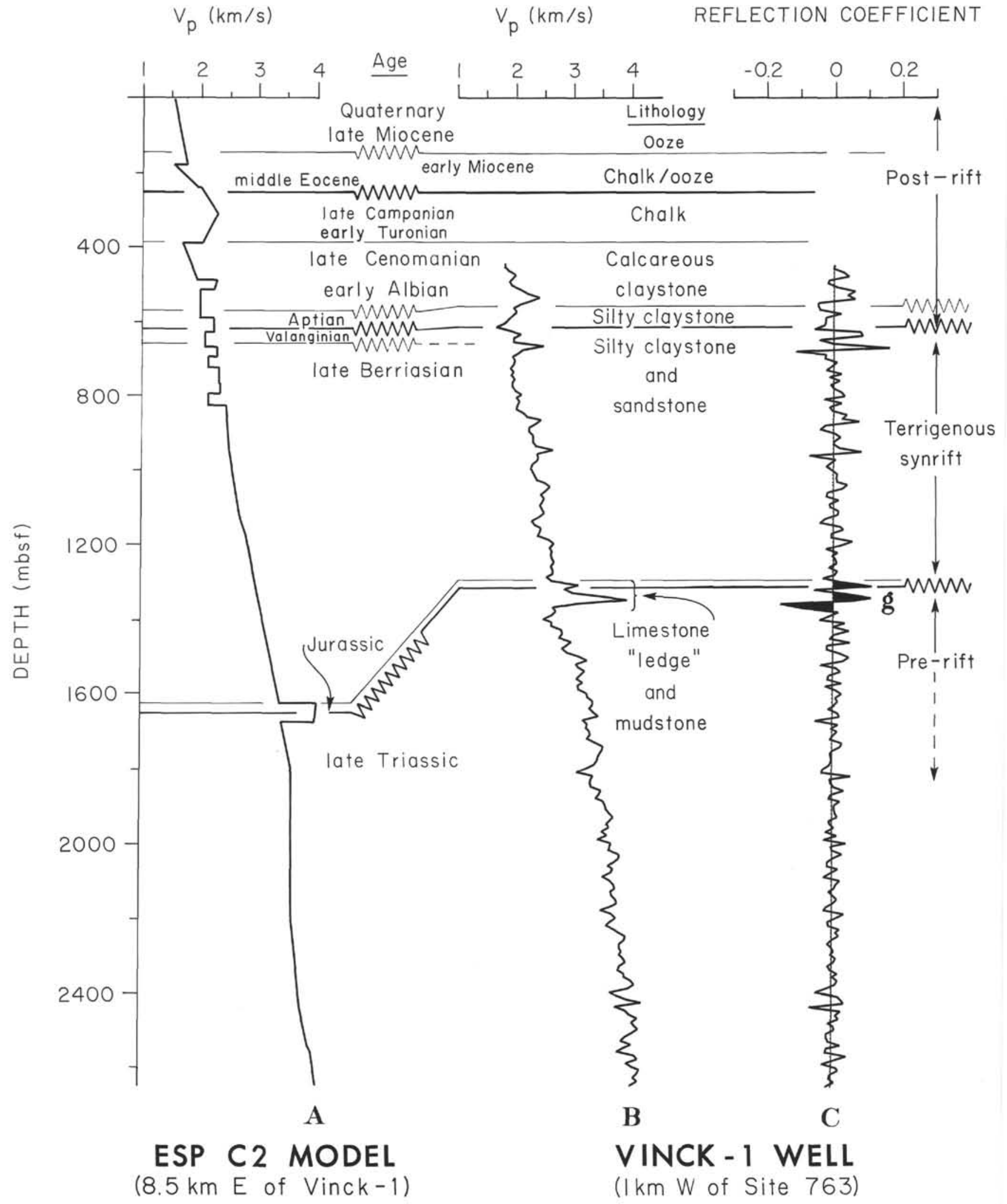

Figure 9. A. Compressional wave velocity $\left(V_{p}\right)$ vs. depth in meters below seafloor (mbsf) from ESP-derived model. B. Vinck-1 downhole sonic tool data. C. Reflection coefficient depth series calculated using Vinck-1 downhole data. 
ing the extensional deformation of the Exmouth Plateau that led to Early Cretaceous seafloor spreading (Haq, von Rad, O'Connell, et al., 1990).

Vinck-1 well $V_{p}$ information was retrieved to a greater depth than at Site 763 , providing data from the synrift sedimentary section and the uppermost portion of the pre-rift basement (Fig. 9). At about $1300 \mathrm{mbsf}$, there lie two isolated high velocity layers, comprising Jurassic claystone and Upper Triassic limestone and mudstone. Similar Triassic lithology was drilled during Leg 122 in the pre-rift basement of the northern Exmouth Plateau and was interpreted as forming part of an outer shelf, shallow carbonate Rhaetian reef complex (Williamson et al., 1989). In the adjacent reflection coefficient series of Figure 9C, the high velocity "ledge" is expressed by a triplet of prominent positive and negative reflection coefficient peaks. The series was constructed using the Vinck-1 sonic tool data and an empirically derived $V_{p}-\rho$ function (Hamilton, 1978).

In the ESP C2 model, a thin high-velocity layer at about $1600 \mathrm{mbsf}$ is responsible for a high-amplitude reflection " $\mathrm{g}$." In ODP line 5 (Fig. 2), "g" can be traced updip toward the projected location of Site 763 and Vinck-1, where it appears to correspond in TWT to the high-velocity "ledge" in Vinck-1. We infer that " $\mathrm{g}$ " closely indicates the top of the Triassic pre-rift basement.

\section{CORRELATION OF DIVERSE SEISMIC DATA SETS}

A comparison of all the diverse data sets and models above (Fig. 10) is required to attach geological ages and causes to major reflective zones observed in the profile of SCS ODP line 5 (Fig. 2). The ESP-model normal incidence synthetic seismogram (Figs. $6 \mathrm{C}$ and 10B) provides accurate traveltime location of major reflectors that are seen in line 5 but does not reproduce the detailed waveforms derived from the higher frequency watergun source. Normal incidence synthetic seismograms calculated with a watergun source and (1) the downhole measurements from Site 763, Vinck-1, and (2) the shipboard-derived physical properties parameters are more appropriately compared with line 5 . These parameters contain small-scale details that are not resolvable with the ESP model. All the seismograms were constructed applying the acoustic case approximation for full reflectivity.

Two seismic sources were used to model the SCS line and compare results. A watergun seismic source wavelet was extracted from the averaged seafloor reflection pulses in the traces of shotpoints 623-629. These shotpoints were assumed free of interference effects from the sub-seafloor reflections. An airgun seismic source, different from that used previously in the ESP C2 synthetic seismograms, was similarly obtained after averaging the near-offset traces of CDP gathers 30993103. Averaging over short distances is intended to reduce the amount of unwanted laterally incoherent noise. In either case, because the source wavelet has a finite length, a reflector at depth is represented by a long seismic pulse in time and not a single short event. It is possible to locate the beginning of each major reflected arrival by pairing it to the corresponding peak in the traveltime reflection coefficient series.

Synthetic seismograms in Figures 10D and 10F illustrate the difference in resolving capability between the watergun vs. the airgun source wavelet, for the same physical properties parameters from Vinck-1. The airgun source produces a reflector corresponding to " $\mathrm{g}$ " that has one major positive pulse (Fig. 10D), similar to the MCS near-offset traces, the ESP data and model of Figures 10A-10B. The watergun source produces a synthetic seismogram that better resembles the deep multipulse reflector of SCS profile in Figure 10G. The reflections from the top and the bottom of a high-velocity layer have an opposite polarity. If the thickness of the bed diminishes sufficiently, the two reflections will combine destructively; that thickness depends on the dominant wavelength of the source. A comparison of frequency spectra of the sources (Fig. 10, inset) reveals that the watergun source has a dominant frequency close to $45 \mathrm{~Hz}$-about twice that of the airgun source. Consequently, the watergun-source seismogram can resolve the reflection coefficient triplet.

Above "g" (top of pre-rift basement), "e" (just below the Cenomanian/Turonian boundary) is an isolated sub-seafloor reflective region in the SCS data (Figs. 2 and 10G). It is difficult to match the arrival times and amplitudes of the seismograms calculated from the physical properties data and the SCS data of line 5; instrument and sampling techniques discussed above may be responsible. Nevertheless, by using the ESP model and traveltime reflection coefficient series we are able to identify " $e$ " approximately as a series of three positive peaks at about 2.2-2.3 s TWT.

\section{SUMMARY}

The major reflectors in MCS CDP line 667, SCS ODP line 5 , and ESP C2 can be tied with the drilling results to the lithologic and age unit boundaries in the vicinity of Site 763 . By comparison to shipboard-derived and downhole physical properties measurements, the ESP-derived physical parameters more accurately describe the reflective character, especially traveltime to the major sedimentary horizons.

$V_{p}, V_{s}, \rho$, and $Q_{p}$ values were obtained for the ESP model by an initial $\tau$-sum construction and a variety of seismic forward modeling techniques that successfully matched the waveform and traveltimes of the major arrivals at all offsets. The parameters of the model are closer in value to the downhole drilling results at Site 763 than the shipboard derived properties probably because they are not as affected by instrument errors, drilling disturbance, and sample rebound effects. Together, they describe the top $300-400 \mathrm{~m}$ of the sediments not sampled by the long-spaced sonic tool, and the synrift and pre-rift section below the extent of drilling at Site 763. The ESP analytical techniques used here incorporate the effects of a finite receiver, source directionality, stacking, and "ghosting."

A correlation between physical properties reflection coefficient series in depth, lithologic, and biostratigraphic units, and the parameters in the ESP model can help date and explain the cause of major reflectors in the ESP data. Three of these reflectors, "b," "e," and "g," occur near the top of LVZ's and represent regionally significant geological events. Below " $b$ " there is a decrease in the degree of induration of late Oligocene chalk, coincident with a threefold increase in the calculated sedimentation rate. Reflector " $\mathrm{e}$ " is the highest amplitude sub-seafloor reflector and is linked to the abrupt disappearance of terrigenous component in the sediments at the Cenomanian/Turonian boundary. Reflector " $\mathrm{f}$ " is found above a breakup unconformity crowning a section of Barremian-Valanginian(?) sediments which were deposited during the extensional deformation of the Exmouth Plateau that led to Early Cretaceous seafloor spreading. Reflector " $\mathrm{g}$ " arises from the top of the Triassic pre-rift basement because of the strong impedance contrast between a thin high-velocity region consisting of shallow-water reefal limestone, and the overlying silty synrift sediments and underlying shallow-water mudstones.

Full-reflectivity synthetic seismograms calculated from the shipboard-derived physical properties agree poorly with the waveform and traveltimes of major reflectors seen in the profile of SCS line 5, as a result of the intrinsic errors mentioned above. However, by using the first-order travel- 


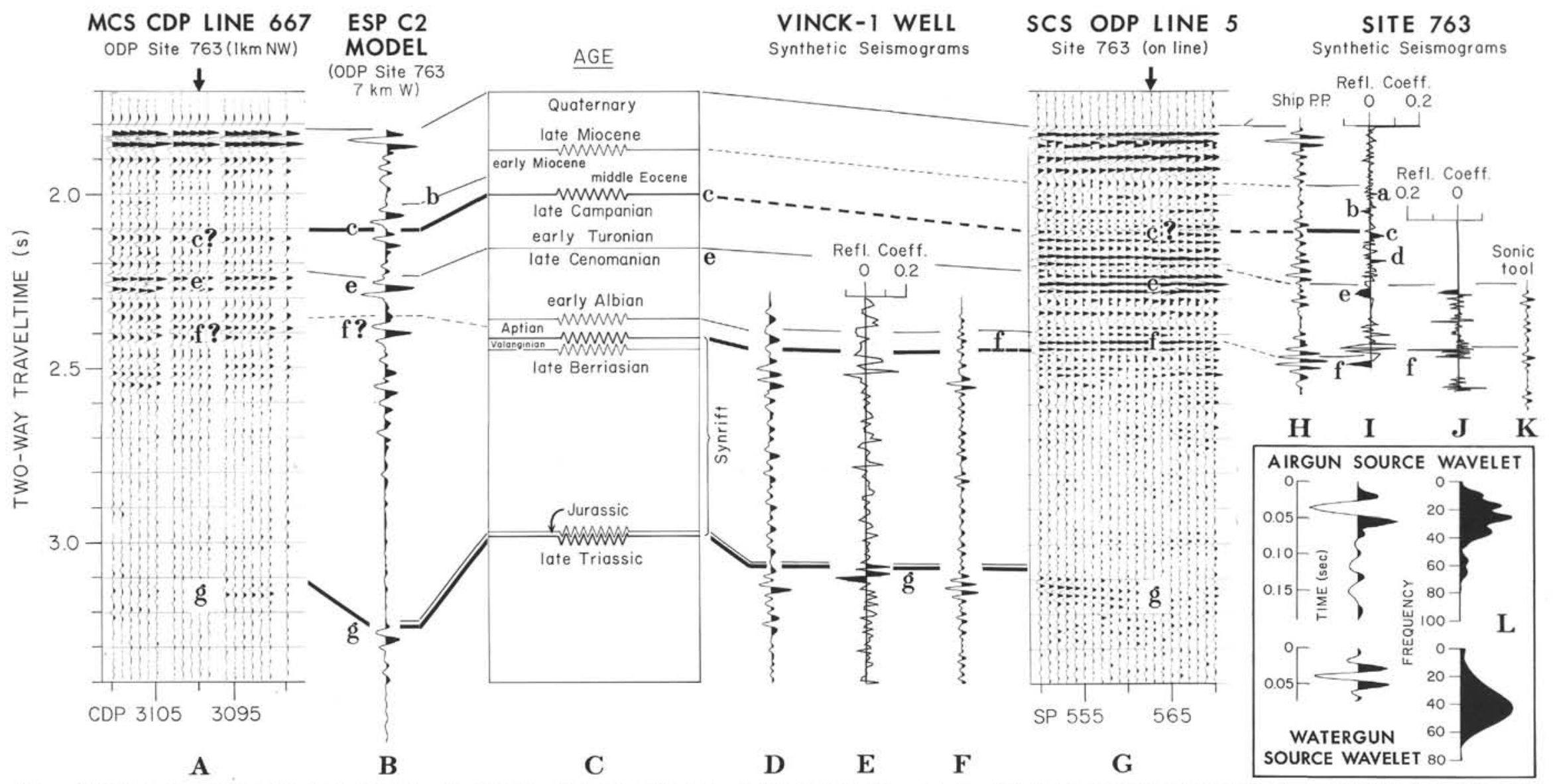

Figure 10. Integral correlation between observed and synthetic seismogram data sets, and biostratigraphic units; all synthetic seismograms calculated at normal incidence. A. Near-offset CDP traces (fold of 1) from profile 667, at projected Site 763, and bandpass-filtered between frequencies 25 and $60 \mathrm{~Hz}$ with high- and low-end cosine tapers of width 10 and $20 \mathrm{~Hz}$, respectively. B. Synthetic seismogram calculated using ESP C2 model parameters, and using airgun source wavelet (inset). Trace has been shifted down in time to align with seafloor reflection and ease correlation between different data sets. C. Biostratigraphic ages (Haq, von Rad, O’Connell, et al., 1990). D. Synthetic seismogram calculated using Vinck-1 downhole data and airgun source wavelet (inset). E. Reflection coefficient depth series calculated from Vinck-1 downhole measurements. F. Synthetic seismogram calculated using Vinck-1 downhole data but using watergun-source wavelet (inset). G. Single-channel seismic data in vicinity of Site 763, bandpass-filtered between frequencies 25 and $60 \mathrm{~Hz}$ with high- and low-end cosine tapers of width 10 and $20 \mathrm{~Hz}$, respectively. H. Synthetic seismogram of raw shipboard derived $V_{p}$ and $\rho$ measurements, seen in Figure 7. I. Corresponding reflection coefficient series of $\mathrm{H}$. J. Reflection coefficient series of K. K. Synthetic seismogram calculated using sonic log seen in Figure 8 and watergun-source wavelet from inset. L. Time and frequency characteristics of airgun and watergun-source wavelets from multichannel and single-channel seismic data sets. Airgun source wavelet is not filtered and has dominant frequency of $25 \mathrm{~Hz}$. Watergun-source wavelet is bandpass-filtered between 25 and $60 \mathrm{~Hz}$ with high- and low-end cosine tapers of width $10 \mathrm{~Hz}$ and $20 \mathrm{~Hz}$, respectively, and has a dominant frequency of $45 \mathrm{~Hz}$. Biostratigraphic boundaries are shown tied to seismograms. Broken lines indicate that some degree of uncertainty in correlation exists. 
times to major reflectors from the ESP seismograms we can correlate major SCS reflectors to units identified by drilling. The greater resolution capability of the single-channel data depends primarily on the dominant wavelength of the seismic source signature which is probably half as long as the airgun source wavelet.

\section{ACKNOWLEDGMENTS}

This study was supported by Purchase Order 20279 ODPUSSAC. We are indebted to many people for their assistance in writing this paper. ESSO Australia allowed us to use and publish the well logs from the Vinck-1 well. Nathan Bangs and John Mutter constructively reviewed early versions of the manuscript and Naomi Katz drafted the illustrations. Jackie Graney was indispensable in coordinating the final submission between two continents. This is Lamont-Doherty contribution 4768.

\section{REFERENCES}

Aki, K., and Richards, P. G., 1980. Quantitative Seismology: New York (W. H. Freeman and Co.).

Barber, P. M., 1982. Paleotectonic evolution and hydrocarbon genesis of the central Exmouth Plateau. APEA J., 22:131-144.

Bullen, K. E., and Bolt, B. A., 1987. An Introduction to the Theory of Seismology: Cambridge (Cambridge Univ. Press).

Chapman, C. H., 1978. A new method for computing synthetic seismograms. Geophys. J. R. Astron. Soc., 54:481-518.

Diebold, J., 1980. The traveltime equation, tau-p mapping and inversion for common midpoint seismic data with applications to the geology of the Venezuela Basin [Ph.D. dissert.]. Columbia Univ., New York.

1987. A new airgun array for CONRAD. Eos, 68:155.

1989. Tau-p analysis in one, two and three dimensions. In Stoffa, P. L. (Ed.), Tau-p: a Plane Wave Approach to the Analysis of Seismic Data: Dordrecht (Kluwer Acad.), 71-117.

Diebold, J. B., and Stoffa, P. L., 1981. The traveltime equation, tau-p mapping, and inversion of common midpoint data. Geophysics, 46:238-254.

Diebold, J. B., Stoffa, P. L., and the LASE Study Group, 1988. A large aperture seismic experiment in the Baltimore Canyon Trough. In Sheridan, R. E., and Grow, J. S. (Eds.), The Atlantic Continental Margin, U.S. Geol. Soc. Am., Geology of North America Ser., I-2:387-398.

Exon, N. F., and Willcox, J. B., 1976. Mesozoic outcrops on the lower continental slope off Exmouth, Western Australia. BMR J. Aust. Geol. Geophys., 1:205-209.

1978. Geology and petroleum potential of Exmouth Plateau area off western Australia. AAPG Bull., 62:40-72.

1980. The Exmouth Plateau: stratigraphy, structure and petroleum potential. Bull. Bur. Miner. Resour., Geol. Geophys. (Aust.), No. 199.

Falvey, D. A., and Mutter, J. C., 1981. Regional Plate tectonics and the evolution of Australia's passive continental margins. BMR J. Aust. Geol. Geophys., 6:1-29.

Gardner, G.H.F., Gardner, L. W., and Gregory, A. R., 1974. Formation velocity and density-the diagnostic basics for stratigraphic traps. Geophysics, 39:770-780.

Hamilton, E. L., 1976. Variations of density and porosity with depth in deep-sea sediments. J. Sediment. Petrol., 46:280-300.

1978. Sound velocity-density relations in sea-floor sediments and rocks. J. Acoust. Soc. Am., 63:366-377.

Haq, B. U., von Rad, U., O'Connell, S., et al., 1990. Proc, ODP, Init. Repts., 122: College Station, TX (Ocean Drilling Program).

Haq, B. U., von Rad, U., and the ODP Leg 122 Scientific Party, 1988. ODP Leg 122 looks at Exmouth Plateau. Geotimes, 33:10-13.

Harding, A. J., Orcutt, J. A., Kappus, M. E., Vera, E. E., Mutter, J. C., Buhl, P., Detrick, R. S., and Brocher, T. M., 1989. The structure of young oceanic crust at $13^{\circ} \mathrm{N}$ on the East Pacific Rise from expanding spread profiles. J. Geophys. Res., 94:1216312196.
Johansen, B., Eldholm, O., Talwani, M., Stoffa, P. L., and Buhl, P., 1988. Expanding spread profile at the northern Jan Mayen Ridge. Polar Res., 6:95-104.

Kennett, B.L.N., 1974. Reflections, rays and reverberations. Bull. Seis. Soc. Am., 64:1685-1696.

Knopoff, L., 1964. Q. Rev. Geophys., 2:625-660.

Larson, R. L., Mutter, J. C., Diebold, J. B., Carpenter, G. B., and Symonds, P. A., 1979. Cuvier Basin: a product of ocean crust formation by Early Cretaceous rifting off western Australia. Earth Planet Sci. Lett., 45:105-114.

LASE Study Group, 1986. Deep structure of the US East Coast passive margin from large aperture seismic experiments (LASE). Mar. Pet. Geol., 3:234-242.

Liu, H. P., Anderson, D. L., and Kanamori, H., 1976. Velocity dispersion due to anelasticity: implications for seismology and composition. Geophys. J. R. Astron. Soc., 47:41-58.

Lorenzo, J. M., Mutter, J. C., Larson, R. L., Buhl, P., Diebold, J. B., Alsop, J., Mithal, R., Hopper, J., Falvey, D., Williamson, P., and Brassil, F., in press. Development of the continent-ocean transform boundary of the southern Exmouth Plateau. Geology.

Mayne, W. H., 1962. Common reflection point horizontal stacking techniques. Geophysics, 27:927-938.

Mithal, R., and Mutter, J. C., 1989. A low-velocity zone within the layer 3 region of $118 \mathrm{Myr}$ old oceanic crust in the western Atlantic. Geophys. J. R. Astron. Soc., 97:275-294.

Mithal, R., and Vera, E. E., 1987. Comparison of plane-wave decomposition and slant stacking of point-source seismic data. Geophysics, 52:1631-1638.

Müller, G., 1985. The reflectivity method: a tutorial. J. Geophys., 58:153-174.

Mutter, J. C., Larson, R. L., Buhl, P., Diebold, J. B., Alsop, J., Mithal, R., Hopper, J., Falvey, D., Williamson, P., and Brassil, F., 1989. Extension of the Exmouth Plateau, offshore northwestern Australia: deep seismic reflection/refraction evidence for simple and pure shear mechanisms. Geology, 17:15-18.

Mutter, J. C., and Zehnder, C. M., 1988. Deep crustal and magmatic processes: the inception of seafloor spreading in the NorwegianGreenland Sea. In Morton, A. C., and Parson, L. M. (Eds.), Early Tertiary Volcanism and the Opening of the NE Atlantic. Geol. Soc. Am. Spec. Publ., 39:35-48.

Parkes, G., and Hatton, L., 1986. The Marine Seismic Source: Dordrecht (D. Reidel).

Powell, D. E., 1976. The geological evolution and hydrocarbon potential of the continental margin off northwest Australia. APEA J., 16:13-24.

Robinson, E. A., 1970. Statistically optimal stacking of seismic data. Geophysics, 35:436-446.

Sengbush, R. L., 1983. Seismic Exploration Methods. (Int. Human Res. Dev. Corp.).

Stoffa, P. L., and Buhl, P., 1979. Two-ship multichannel seismic experiments for deep crustal studies: expanded spread and constant offset profiles. J. Geophys. Res., 84:7645-7660.

Stoffa, P. L., Buhl, P., Diebold, J. B., and Wenzel, F., 1981. Direct mapping of seismic data to the domain of intercept time and ray parameter-a plane wave decomposition. Geophysics, 46:255-267.

Veevers, J. J., and Cotterill, D., 1978. Western margin of Australia: evolution of a rifted arch system. Geol. Soc. Am. Bull, 89:337-355.

Veevers, J. J., and Johnstone, M. H., 1974. Comparative stratigraphy and structure of the Western Australian margin and the adjacent deep ocean floor. In Veevers, J. J., Heirtzler, J. R., et al., Init. Repts. DSDP , 27: Washington (U.S. Govt. Printing Office), 571-585.

Vera, E. E., 1987. On the connection between the Hergoltz-WiechertBateman and tau-sum inversions. Geophysics, 52:568-570.

Vera, E. E., Mutter, J. C., Orcutt, J. A., Harding, A. J., Kappus, M. E., Detrick, R. S., and Brocher, T. M., 1990. The structure of 0to 0.2 m.y.-old oceanic crust at $9^{\circ} \mathrm{N}$ on the East Pacific Rise from Expanded Spread Profiles. J. Geophys. Res., 95:15529-15556.

von Rad, U., and Exon, N. F., 1983. Mesozoic-Cenozoic sedimentary and volcanic evolution of the starved passive continental margin off northwest Australia. In Watkins, J. S., Drake, C. L., and Sheridan, R. E. (Eds.), Studies in Continental Margin Geology: AAPG Mem., 34:253-281. 
von Stackelberg, U., Exon, N. F., von Rad, U., Quilty, P., Shafik, S., Beiersdorf, H., Seibertz, E., and Veevers, J. J., 1980. Geology of the Exmouth and Wallaby Plateaus off northwest Australia: Sampling of seismic sequences. BMR J. Aust. Geol. Geophys., 5:113-140.

Wenzel, F., Stoffa, P. L., and Buhl, P., 1982. Seismic modeling in the domain of intercept time and ray parameter. IEEE Trans. Acoust. Speech Signal Process, 30:406-423.

Widess, M. B., 1973. How thin is a thin bed? Geophysics, 38:1176-1180.

Williamson, P. E., Exon, N. F., Haq, B. U., von Rad, U., and Leg 122 Shipboard Scientific Party, 1989. A North West Shelf Triassic reef play: results from ODP Leg 122. APEA J., 29:328-344.

Date of initial receipt: 4 June 1990

Date of acceptance: 14 April 1991

Ms 122B-117

\section{APPENDIX A}

Receiver, Source, Stacking, and Free Surface Effects

The frequency-ray parameter $(\omega-p)$ response of (1) a multiphone finite length receiver, (2) multisource array, and (3) the stacking of the traces inside a given source-receiver offset "bin" have identical mathematical treatments. The source wavelet shape is controlled by the frequency-ray parameter response of free-surface interactions.

\section{Finite Receiver}

Let us consider a plane wavefront with ray parameter $p$ and time function $a(t)$ impinging on a receiver consisting of $N$ point phones (Fig. A1). $d$ is the distance between phones, and a point at a distance $(m d)$ from the first phone is chosen as reference. The time when the wavefront reaches the $i$-th phone is

$$
t_{i}=(i-m-1) \Delta t
$$

where

$$
\Delta t=p d .
$$

The signal $A(t, p)$ seen by the receiver is the sum of the signals $a(t)$, seen at each phone with the proper time shift, that is

$$
A(t, p)=\sum_{i=1}^{\mathrm{N}} a\left(t-t_{i}\right)
$$

or in the frequency domain

$$
A(\omega, p)=a(\omega) \sum_{j=1}^{N} \mathrm{e}^{-j \omega t_{i}}
$$

where $A(\omega, p)$ and $a(\omega)$ are the Fourier transform of $A(t, p)$ and $a(t)$, respectively, $j$ is the imaginary unit, and $\omega=2 \pi f$ is the angular frequency.

Normally $m=(N-1) / 2$ so that the reference point is the receiver midpoint. In this case the sum in equation (A4) can be simplified and the normalized receiver response $R(\omega, p)=(A(\omega, p) / a(\omega)) / N$ is

$$
R(\omega, p)=\frac{\sin \left(\frac{N \omega \Delta t}{2}\right)}{\sin \left(\frac{\omega \Delta t}{2}\right)}
$$

We used a 48-channel streamer consisting of 30 phones in each channel at $1.6 \mathrm{~m}$ spacing to estimate the receiver response. The response function was incorporated into the full-reflectivity synthetic seismogram calculations. The function (A5) for this receiver is shown in Figure A2. The main effect of the finite receiver is the attenuation of the high frequencies. The larger the ray parameter, the larger the attenuation.

\section{Source Directionality}

Source directionality for a linear array of airguns behind a towing ship is physically analogous to the frequency-p response of a multi-

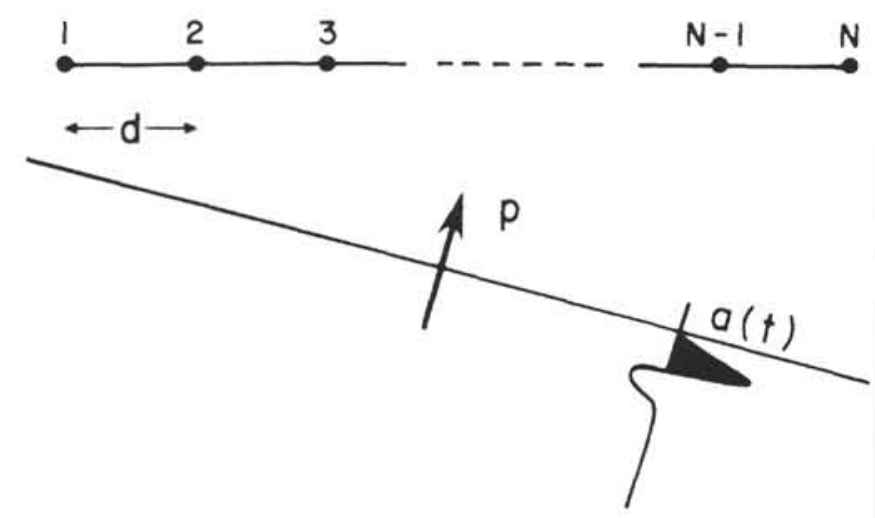

Figure A1. Geometry involved in calculating the $N$-phone receiver response.

phone finite length receiver. Let us assume that the airgun array used in the ESP C2 experiment (Fig. 3) can be approximated by a coplanar five airgun array. Attenuation at $20 \mathrm{~Hz}$, the dominant frequency in the source, using the function (A5), is less than a few percent for all values of $p$ less than $0.666 \mathrm{~s} / \mathrm{km}$ (1/water velocity). Thus the combinatorial seismic pulse of our wide array should be seen at sufficiently far distances as a point source and need not be considered during full-reflectivity calculations.

\section{Stacking}

Stacking of the traces in a given source-receiver offset "bin" to produce a single seismogram at the bin midpoint, can be analyzed by the same approach followed above for the $N$-phone receiver response. In both cases the same signal is added several times with different time shifts. Assuming equispaced traces in the bin, for the $\omega-p$ effect produced by the stacking process, one obtains a formula identical to (A5), except that now $R$ is the normalized ratio between the output and input trace spectrum, $N$ is the number of traces in the bin, $d$ is the trace spacing, and $p$ is the absolute value of the difference between the data and stacking ray parameters. Figure A3 shows the response for eight traces in a $50 \mathrm{~m}$ bin, stacked along a slant trajectory defined by $p=0.125 \mathrm{~s} / \mathrm{km}(8 \mathrm{~km} / \mathrm{s})$; this case is typical of the processing performed with the ESP data. There is no distortion of the pulse shape for arrivals having the same phase velocity (ray parameter) as the stacking velocity. Arrivals with a different phase velocity, however, do not add in phase, which causes attenuation of the high frequencies. The larger the difference between the arrival phase velocity and stacking velocity, the larger the attenuation. Although in calculating $x-t$ seismograms with full-reflectivity, we also applied the stacking response, the effect was minimal because of the additional and larger attenuation by the effect of the free surface.

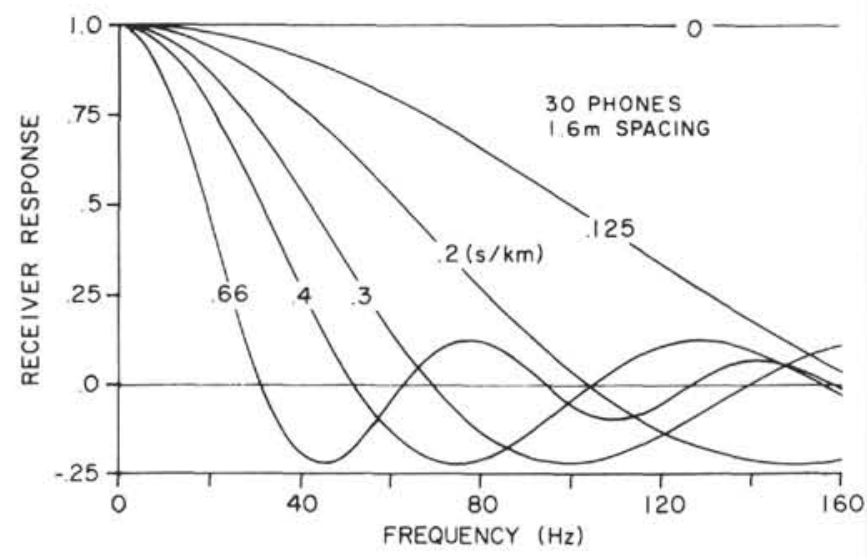

Figure A2. Frequency response for receiver array used in calculating synthetic seismograms with the full-reflectivity. 


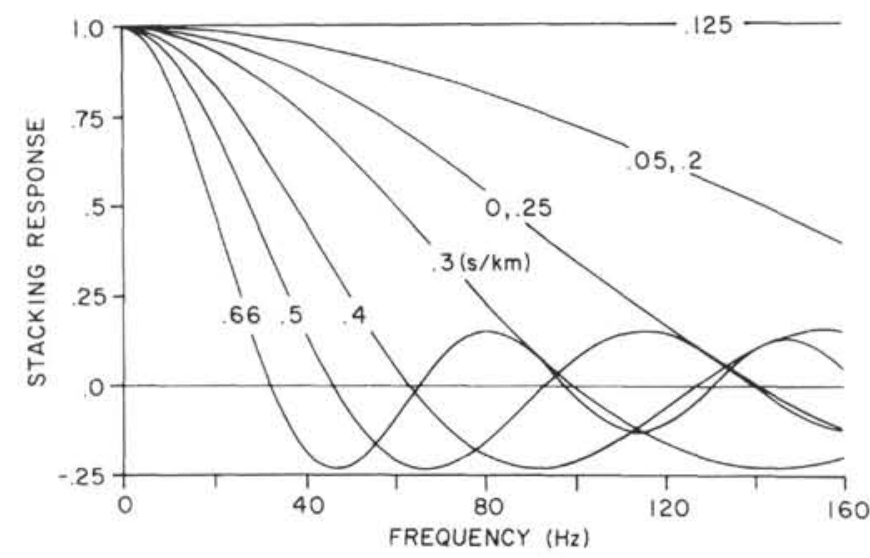

Figure A3. Frequency response for stacking of eight traces at $7.14 \mathrm{~m}$ ( $50 \mathrm{~m}$ bin). Stacking ray parameter is $0.125 \mathrm{~s} / \mathrm{km}$. Response is shown for arrivals with ray parameters between 0 and $0.66 \mathrm{~s} / \mathrm{km}$. Response depends on absolute value of difference between arrival ray parameter and the stacking ray parameter. In calculating $x-t$ seismograms with full-reflectivity, we also estimated stacking response to make comparison with data more accurate (see Fig. 4).

\section{Free Surface Effect or "Ghosting"}

The computation of the reflection response of a layered medium to plane waves is normally carried out considering an infinite upper half-space. The effect of the free surface is added at a later stage and involves the interaction of the plane waves with the free surface (sea surface) near the source and the receiver, also known as "ghosting." Consider an upgoing plane wave front of ray parameter (horizontal slowness) $p$ impinging on a receiver at depth $d_{R}$ (see Fig. A4). In the case of an infinite upper half-space, the wave front would interact with the receiver once and would then continue traveling upward indefinitely. The free surface, however, reflects this front back producing a downgoing front that is $180^{\circ}$ phase-reversed and that reaches the receiver $t_{R}$ seconds later than the upgoing front. The time delay $t_{R}$ can be easily calculated as

$$
t_{R}=2 d_{R} q
$$

where

$$
\theta=\frac{\cos \theta}{v}=\sqrt{\frac{1}{v^{2}}-p^{2}}
$$

is the vertical slowness. The signal $A(t, p)$ seen at the receiver, is the sum of the upgoing front, $a(t)$, and the downgoing reflected front, $b(t)$, with the proper time delay, $t_{R}$. Ideally, the free surface reflection coefficient is -1 and thus $b(t)=-a(t)$. (In general, the free surface may not be a perfect reflector and $b(t)=-C a(t)$ where $C$ is less than one.)

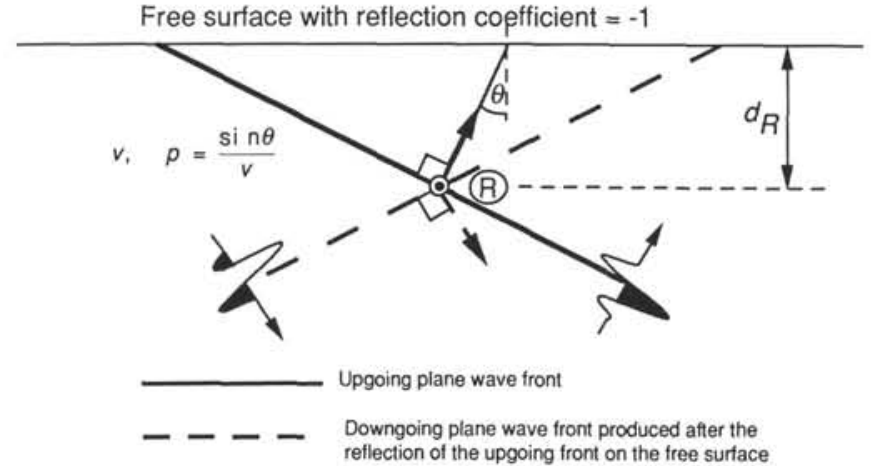

Figure A4. Geometry involved in calculating free surface effect response.
If, for convenience, we consider that the time at which the upgoing front reaches the receiver is defined as $t=-1 / 2 t_{R}$, the time for the downgoing front is $t=-1 / 2 t_{R}+t_{R}=1 / 2 t_{R}$, and $A(t, p)$ is then:

$$
A(t, p)=a\left(t+\frac{1}{2} t_{R}\right)-a\left(t-\frac{1}{2} t_{R}\right)
$$

In frequency domain, equation (A8) is

$$
A(\omega, p)=a(\omega)\left(\mathrm{e}^{\frac{i \omega t_{R}}{2}}-\mathrm{e}^{\frac{-i \omega t_{R}}{2}}\right)
$$

where $\omega$ is the angular frequency and $A(\omega, p)$ and $a(\omega)$ are the Fourier transform of $A(t, p)$ and $a(t)$ respectively. Equation (A9) can be simplified and the response of the free surface at the receiver is

$$
\frac{A(\omega, p)}{\mathrm{a}(\omega)}=2 \mathrm{i} \sin \left(\frac{\omega t_{R}}{2}\right) .
$$

Following exactly the same steps, an expression analogous to (A10) can be found for the response at the source. The total effect of the free surface on the recorded signal, $R(\omega, p)$, is the product of the response at the source and the receiver:

$$
R(\omega, p)=-4 \sin \left(\frac{\omega t_{S}}{2}\right) \sin \left(\frac{\omega t_{R}}{2}\right)
$$

where $t_{S}$ is computed using (A6) and (A7) but using $d_{S}$, the source depth, instead of $d_{R}$.

Figure A5 shows the effect of the free surface as a function of frequency for several $p$ 's. This effect significantly attenuates arrivals at $p$ of about $0.6 \mathrm{~s} / \mathrm{km}$ and greater. In our data for ESP C2 (Fig. 4) this $p$ range corresponds to mainly wide aperture seafloor reflections at offsets greater than about $8 \mathrm{~km}$.

\section{APPENDIX B}

\section{Reflectivity Calculations}

The reflectivity method comprises two parts: the computation of the plane wave $\omega-p$ response of the medium (reflectivity), and the transformation and integration of the reflectivity function to obtain the $x-t$ seismograms. For the reflectivity part, we employed a recursive method that uses frequency independent reflection coefficients to propagate the reflectivity across the layer interfaces, and complex $2 \times$ 2 phase matrices within each layer (Kennett, 1974; Müller, 1985). For the integration we followed Wenzel et al. (1982) in which the reflectivity function is first transformed from the frequency to the time domain to obtain $\tau-p$ seismograms, and the $x-t$ seismograms are then computed by slant stacking in $\tau-p$.

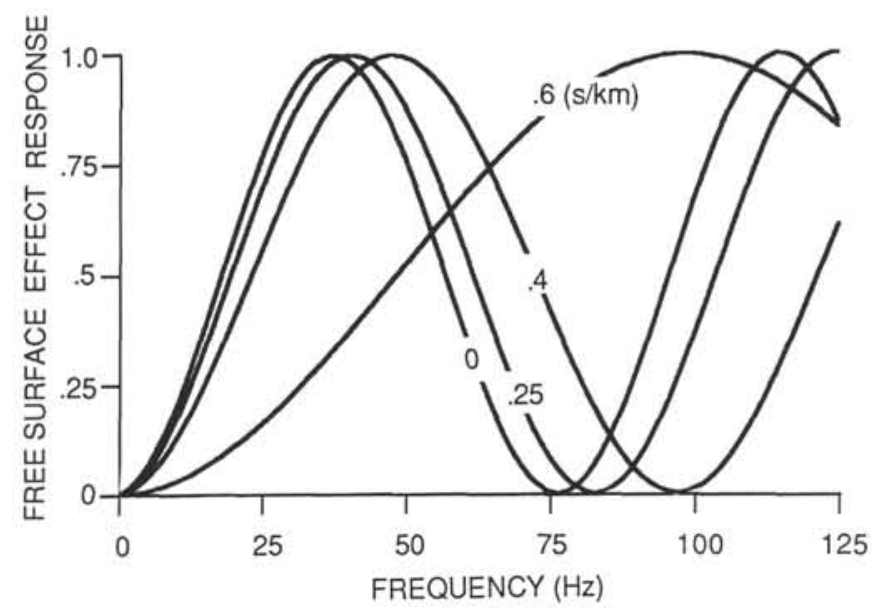

Figure A5. Frequency response for an airgun and receiver both at depth of $10 \mathrm{~m}$ below free surface. 